\title{
Lugeon tests at partial saturation: experimental and empirical contributions
}

\author{
Brendon R. Jones ${ }^{1,2}$, J. Louis Van Rooy ${ }^{1}$ and Matthys A. Dippenaar ${ }^{1 *}$ \\ ${ }^{I}$ Engineering Geology and Hydrogeology, Department of Geology, University of Pretoria, Pretoria, South Africa \\ ${ }^{2}$ GaGE Consulting, Fourways, Johannesburg, South Africa \\ *Corresponding author. matthys.dippenaar@up.ac.za/madippenaar@gmail.com /+27124203117
}

ORCID: Jones 0000-0003-2611-1940; Van Rooy 0000-0003-4708-6991; Dippenaar 0000-0002-6807-1353

\begin{abstract}
Implications of improved understanding of variably saturated flow are numerous, especially given the complexity, heterogeneity and anisotropy of the intermediate fractured vadose zone. One such an implication is the quantification of water movement for engineering purposes, as flow through unsaturated discontinuities cannot be quantified through commonly applied saturated approaches. This paper presents an experimental study using geotechnical centrifuge modelling to investigate flow behaviour during Lugeon tests, through the fundamental concept of a smooth, clean, open fracture, at partial saturation. The study comprised flow visualisation experiments conducted on transparent replicas of horizontal and inclined fractures, with water injected under a consecutive series of ascending and descending pressures. Findings from the research proved that preferential flow occupied the minority of cross-sectional area despite the hydraulic pressure. Furthermore, the observed behaviour of these preferential pathways indicated non-linear flow. Deviation from linearity occurred at small fluxes and is likely as a result of inertial effects due to fluid bending at the inlet source into the fracture. In order to assess these non-linear results, the Forchheimer relationship was used to predict the flow rate at the imposed hydraulic heads. As the width of the fracture could not be used as input into the equation, due to the lack of saturation across its width, the width of the flow path was used instead. This resulted in the predicted results comparing well with the measured flow rates, and indicates that the Forchheimer relationship can potentially be used to describe unsaturated flow in discrete, open fractures.
\end{abstract}

Keywords: Forchheimer equation; Reynolds number; water pressure test; geotechnical centrifuge; flow mechanism; unsaturated; packer. 


\section{ACKNOWLEDGEMENTS}

Gratitude is extended to the South African Water Resource Commission (www.wrc.org.za) for their financial support by projects K5/2326, together with the National Research Foundation (NRF). The authors furthermore acknowledge the journal, its editors and reviewers. The authors declare no conflict of interest.

\section{LIST OF SYMBOLS}

$Q \quad$ Volumetric flow rate $\left[\mathrm{L}^{3} \mathrm{~T}^{-1}\right]$

$\nabla P \quad$ Pressure gradient $\left[\mathrm{ML}^{-1} \mathrm{~T}^{-2}\right]$

$w \quad$ Fracture width [L]

A Linear Forchheimer coefficient $\left[\mathrm{ML}^{-5} \mathrm{~T}^{-1}\right]$

$B \quad$ Non-linear Forchheimer coefficient $\left[\mathrm{ML}^{-8}\right]$

$e_{h} \quad$ Hydraulic aperture of idealized parallel smooth fracture [L]

$\mu \quad$ Dynamic viscosity of fluid $\left[\mathrm{ML}^{-1} \mathrm{~T}^{-1}\right]$

$k \quad$ Intrinsic permeability defined as $e^{2} / 12\left[\mathrm{~L}^{2}\right]$

$\rho \quad$ Fluid density $\left[\mathrm{ML}^{-3}\right]$

$A_{h} \quad$ Cross-sectional area (equal to $\left.e w\right)\left[\mathrm{L}^{2}\right]$

$\beta \quad$ Non-Darcy flow coefficient or Forchheimer coefficient $\left[\mathrm{L}^{-1}\right]$

Re Reynolds number [-]

$v \quad$ Bulk velocity $\left[\mathrm{LT}^{-1}\right]$

$F_{o} \quad$ Forchheimer number [-]

$L u \quad$ Lugeon number $\left[\mathrm{L}^{2} \mathrm{~T}^{-1} \mathrm{M}^{-1}\right]$

$L \quad$ Length of the Lugeon test segment [L

$P_{e} \quad$ Effective pressure in the Lugeon test segment [M]

$P \quad$ Hydraulic pressure

$T \quad$ Transmissivity $\left[\mathrm{L}^{2} \mathrm{~T}^{-1}\right]$

$d H \quad$ Change in head [L]

$r_{o} \quad$ Radius of influence during the Lugeon test [L]

$r_{w} \quad$ Borehole radius [L] 


\section{INTRODUCTION}

Lugeon tests are the most common method used to assess the permeability of rock masses for engineering purposes, and were primarily developed to determine groutability of dam foundations. However, uncertainties arise through the often-unsaturated state of the rock mass, and the associated complexity of flow regimes and flow mechanisms in such unsaturated fractured geologic media. Both Ewert (1997a) and Widmann (1996) emphasised the uncertainties pertaining to Lugeon tests, and called early on for the better quantification and characterisation of flow path geometries, with limited studies that subsequently builds on the authors requests. Numerous authors have improved our understanding of Lugeon testing when using it to characterise hydrogeological regimes of fractured rock masses (see for e.g. Chen et al. 2015a; Croisé et al. 2004; Gustafson and Fransson 2006; Hamm et al. 2007; Kayabasi et al. 2015; Ku et al. 2009; Kurikami et al. 2008; Le Borgne et al. 2007; Mejías et al. 2009; Mollah and Sayed 1995; Nappi et al. 2005; Öge and Çırak 2017; Quinn 2009; Quinn et al. 2011). However, no previous studies have aimed to link the Lugeon-value with flow mechanisms and associated flow regimes (e.g. Reynolds number), more so within discrete fractures by isolating individual processes at laboratory scale. Although important, most previous research relating to Lugeon testing are all implicitly in-situ (field-based), assess the rock mass as a bulk media (i.e. not discrete), and assume saturated state or have otherwise failed to address unsaturated (preferential) flow. Recently, Jones et al. (2018) have presented results for a dam site that shows an increasingly better correlation between Lugeon and grouting data for the foundation rock mass towards the river section. A possible contributor to this trend is the wetter nature of the fractures towards the river section, as opposed to the dry and unsaturated nature of fractures on the upper flanks, which may have influenced the flow regimes during the Lugeon tests.

In light of this, and building on the literature supplied hereafter, this paper presents an experimental study that assesses the flow behaviour when conducting Lugeon tests under conditions of variable saturation in an initially dry free-draining, smooth, clean, open, discrete fracture using geotechnical centrifuge modelling. The aim is achieved by qualitatively examining the geometry of the flow paths within the fractures, whilst measuring the flow rate under a series of ascending and descending pressure intervals. The Forchheimer relationship is used to predict the flow rate at the imposed hydraulic heads using the width of the flow path within the fracture. Empirical and experimental contributions eventually supply insight into improved interpretation and understanding of Lugeon tests at partial saturation. 


\subsection{Partially saturated fracture flow mechanisms}

The intermediate fractured vadose zone comprises rock masses under conditions of partial saturation. Flow through this unsaturated rock mass cannot be quantified through commonly applied saturated approaches, and needs to be addressed for varying saturation and flow path characteristics. In this region above the water table, the water phase is usually at a negative potential, and cannot completely fill the void space of the fracture, with the remainder of the fracture being filled by air (Zimmerman and Yeo 2000). These mixed air-water flows behave differently from water-saturated systems, whereby the most notable implication of partial saturation of fracture networks is that gravity does not necessarily force water down near-vertical discontinuities (Dippenaar and Van Rooy 2016). Although within individual fractures, gravity plays a first-order role in creating vertically extensive liquid phase structures, their subsequent intersections act as capillary barriers that restrict matrix communication (Nicholl et al. 1994). The attraction of water molecules to the surface is defined as adhesion, whereas the interaction between the different water molecules is defined as cohesion. In natural fractures at lower moisture contents, water is therefore more likely to interact with matrix porosity generally yielding more surface area than open fractures, whereas cohesion will result in gravity flow in open fractures at higher saturations (Jones et al. 2017a).

Moreover, the formation of the different flow mechanisms in variably saturated fractures are dependent on various factors, including the force interactions between gravity, surface tension, capillary pressure, and viscous forces. These interactions result in complex flow phenomena in unsaturated media such as episodic fluxes, intermittent fluxes and preferential flow paths (Su et al. 1999). Several flow mechanisms have been observed to occur in fractures at unsaturated conditions during flow visualization experiments as well as conceptual modelling studies, and include; film flow, droplet flow, and flow occurring as rivulets, with Ghezzehei (2004) presenting that the boundaries between flow regimes can occur over a range of contact angles and fluxes. Film flow (as presented by e.g.: Or and Tuller 2000; Tokunaga and Wan 1997; Tokunaga and Wan 2001) occurs as thin films of water flowing along the fracture surface without having to fully saturate it. Doe (2001), in his review, highlights that film flow considers scenarios where there is sufficient water supply and the material exhibits a contact angle of zero. For scenarios outside of these boundaries, a droplet flow conceptual model is explored by Doe (2001), and echoed by Or and Ghezzehei (2007), which incorporates single-wall (drops) and double-wall (liquid bridges) features. An additional flow mechanism is that of rivulet flow, of which there are three possible scenarios, as 
initially presented by Su et al. (1999) and later by Dragila and Weisbrod (2003). The three scenarios are dependent on flow rates, whereby (i) at low flow rates, continuously snapping rivulets form liquid bridges within the fracture; (ii) at medium flow rates, rivulets form and only snap at the fracture's end; and (iii) at high flow rates, rivulets that form are maintained throughout the fracture. These findings were confirmed by Brouwers and Dippenaar (2018) during their experiments investigating flow mechanisms at the soil-rock interface, as well as by Dippenaar and Van Rooy (2019) and Jones et al. (2019) based on partially saturated fracture flow experiments.

\subsection{Empirical and mathematical relationships for fracture flow}

The quantification of flow through discrete fractures considers a simple model concept of two smooth parallel plates, assuming the matrix as impermeable and that saturated laminar flow conditions apply. Thereafter, the flux or discharge $(Q)$ occurring through a single discrete fracture can be determined using a basic analytical method derived from the Navier-Stokes equation, and is known as the cubic law due to the proportionality of the flux to the third power of aperture (e.g. Bear 1972; Dippenaar and Van Rooy 2016; Silberhorn-Hemminger et al. 2005; Singhal and Gupta 2010). The validity of the cubic law, however, is often queried given the assumptions from this strong oversimplification of natural conditions (see for e.g. Aydin 2001; Cook 1992; Dippenaar and Van Rooy 2016; Lee and Farmer 1993; Pyrak et al. 1985; Raven and Gale 1985; Singhal and Gupta 2010; Sisavath et al. 2003; Witherspoon 1986). Furthermore, the cubic law cannot be used to quantify flow through discrete fractures at partial saturation as the key assumption that the fracture must be saturated is violated, particularly in vertical fractures as concluded by Jones et al. (2017a).

Both Darcy's law and the cubic law, which describe flow by a linear relation between the flow rate and pressure drop, are only valid when the inertial forces are negligible compared with viscous forces, and generally occurs at low flow rates (Zhou et al. 2015). Forchheimer's law (as introduced by Forchheimer 1901) has been most widely used to describe non-linear flow in fractures and porous media (Eq. 1).

$-\nabla P=A Q+B Q^{2}$

Coefficients $A$ and $B$ are, respectively, the linear and nonlinear coefficients related to the fluid properties and the medium geometries described as per Eq. 2 and Eq. 3 (Chen et al. 2015b).

$A=\frac{\mu}{k A_{h}}=\frac{12 \mu}{w e_{h}^{3}}$ 
$B=\frac{\beta \rho}{A_{h}^{2}}=\frac{\beta \rho}{w^{2} e_{h}^{2}}$

Forchheimer's law ultimately reduces to Darcy's law when the nonlinear effect becomes negligible, i.e., $\beta=0$ (Zhou et al. 2015).

Schrauf and Evans (1986) showed that by using dimensional analysis, the coefficients $A$ and $B$ may be reduced to the dimensionless coefficients $a_{D}$ and $b_{D}$, respectively, and the Forchheimer equation (as presented in Eq. 1) can therefore be rewritten for one-dimensional flow in fractures as per Eq. 4 (Chen et al. 2015b):

$-\nabla P=a_{D} \frac{\mu}{e_{h}^{3} w} Q+b_{D} \frac{\rho}{e_{h}^{3} w^{2}} Q^{2}$

The coefficient $a_{D}$ depends on the characteristic length of the fracture geometry, or the hydraulic aperture $\left(e_{h}\right)$, and will differ for flow between parallel plates and flow in a pipe (Chen et al. 2015b). For a parallel plate set-up, where the characteristic length (or $e_{h}$ ) refers to the aperture between the opposite plates, a value of 12 (Chen et al. $2015 \mathrm{~b}$ ) is used for the coefficient $a_{D}$. The coefficient $b_{D}$ is proportional to the friction factor $f_{D}$ such that $b_{D}=f_{D} / 2$ (as cited in Chen et al. 2015b; Louis 1969; Schrauf and Evans 1986).

Two dimensionless numbers, the Reynolds number $(R e)$ and the Forchheimer number $\left(F_{o}\right)$ are used to predict the point at which linear flow terminates, and non-Darcy flow behaviour begins. The Reynolds number $(R e)$ is defined as the ratio of inertial forces to viscous forces, and is given by Eq. 5 (Brush and Thomson 2003; Chen et al. 2015b; Ranjith and Darlington 2007; Zhou et al. 2015; Zimmerman et al. 2004).

$R e=\frac{\rho v e_{h}}{\mu}=\frac{\rho Q}{\mu w}$

Describing flow from Lugeon tests using the $R e$ is complicated due to the $R e$ not being uniquely defined over the radial flow area as the hydraulic gradient decreases away from the borehole wall along the fracture. In this regard, both Iwai (1976) and Quinn et al. (2011), calculated the $R e$ for flow at the borehole wall where velocities are highest. The Forchheimer number $\left(F_{o}\right)$ is defined as the ratio of non-linear to linear pressure losses in the Forchheimer's law, and is defined by Eq. 6 (Chen et al. 2015b; Cherubini et al. 2012; Javadi et al. 2014). 


$$
F_{O}=\frac{B Q^{2}}{A Q}=\frac{B Q}{A}
$$

The physical meaning of $F_{o}$ represents the ratio of the pressure gradient required to overcome inertial forces to that of viscous forces, and it accounts for both velocity $(v)$ and the geometry or structure of the medium $(b)$ (as cited in Chen et al. 2015b; Cherubini et al. 2012; Javadi et al. 2014; Ruth and Ma 1992; Zeng and Grigg 2006).

Previous laboratory experiments using single fractures observed flow to deviate from linearity at a critical Reynolds number $\left(R e_{c}\right)$ of between 1 and 5 (Konzuk and Kueper 2004; Nicholl et al. 1999; Zimmerman et al. 2004). Causes of non-linearity are attributed to surface roughness (asperities), aperture variations, and obstructions or contact areas between fracture walls (Konzuk and Kueper 2004; Raven and Gale 1985). Iwai (1976) also observed that inertial effects due to fluid bending at the entrance to the fracture can contribute to nonlinearity.

Jones et al. (2017a) importantly conclude that, with regards to variably saturated fracture flow, there needs to be a better emphasis of how, rather than how much, fluid flows through discrete fractures under conditions of variable saturation. Black box model approaches (i.e. bulk flow methods) can generally be applied with a fair amount of confidence, although the problem faced relates to how water is transferred through individual fractures (Jones et al. 2017a). Furthermore, bulk flow methods generalise fluxes on a regional scale, and do not contribute to the fundamental research questions as to which geometrical and fluid properties govern variably saturated flow (see for e.g. Berkowitz 2002; Neuman 2005), because they do not exclusively focus on discrete fractures. Ultimately, any classical volume-effective approach (such as the Richards' equation) is therefore questionable.

\subsection{Lugeon testing and pressure-flux relationships}

In practice, the common method of assessing water flow through fractured rock masses for engineering purposes is by using the Lugeon test or water pressure test (see for e.g. Ewert 1997b; Heitfeld and Krapp 1981; Houlsby 1976; Lancaster-Jones 1975; Pearson and Money 1977; Quiñones-Rozo 2010; Royle 2002; Yihdego 2017). The test was mostly developed to determine groutability and efficiency of ground treatment for dam foundations, and is a type of constant-head test that uses inflatable packers to isolate a section of a borehole for water injection through a perforated pipe at a constant pressure. This test section is either conducted between a single packer and 
the base of a borehole, or a section between two packers. Generally, five tests are conducted per borehole section at different constant pressures, for a period of 10 minutes each, with both water pressure and flow rates being recorded for each stage. The recorded flow rates (at prototype scale) are used to calculate the $L u$-number for each step by using Eq. 7 (Nonveiller 2013; Palmstrom and Stille 2010):

$L u=\frac{Q}{P_{e} L}$

The average value of the flow rate and the water pressure is then used to calculate the Lugeon value for a specific stage.

Observation of the patterns of the Lugeon-value over each pressure stage, allows flow characteristics to be deduced and a representative Lugeon value to be chosen. Based on the five flow types as introduced by Houlsby (1976) a single most representative value is chosen from the $L u$ numbers that are calculated for each of the five steps, to give a Lugeon-value. The Lugeon test gives a continuous vertical distribution of hydraulic properties through a rock mass, and is essential to the proper design of the hydrogeological program for the given engineering purpose.

During these tests, flow from the borehole along the fracture is initially turbulent, and becomes laminar farther from it (Widmann 1996). Ewert (1985) and Ewert (1992) argue that Darcy’s Law does not apply in these tests, mostly due to the characteristic anisotropy and large-scale inhomogeneity's in the rock mass, coupled with the unknowability of the nature and distribution of flow paths. Therefore, the coefficient of permeability as defined by Darcy's Law cannot be determined quantitatively (Weaver and Bruce 2007). Particular to grout operations, Widmann (1996) state that prior to the interpretations of any Lugeon test data, the structure and geometry of the flow paths need to be understood and conceptualized, as they may vary considerably at the local intersection of the borehole and fracture. Important geometric factors of flow paths are both the cross-sectional area of flow and the structure of the flow paths, which determine the change in dimensions of the flow area away from the borehole (Widmann 1996). Additionally, Widmann (1996) also states that considerable pressure losses are expected at the intersection of the borehole with a fracture at high flow velocities. Despite its limitations, these tests remain the only practical method of investigating the permeability of fractured rock masses for engineering purposes. 
The $L u$-value can also be expressed by the tangent slope of the plot of the pressure versus flux $(P Q)$ diagram (Ewert 1997b). Furthermore, Nonveiller (2013) suggests that this tangent slope of the $P Q$ diagram is a valid expression of the Lugeon value during Lugeon tests, and expresses a representative value at any point on the diagram. Using the approach to that of Quinn et al. (2011), the value of $P Q$ where the graph is linear provides the transmissivity $(T)$ for the test interval by using the Thiem equation shown in Eq. 8 (Wenzel 1936).

$T=\frac{Q}{2 \pi d H} \ln \left(\frac{r_{o}}{r_{w}}\right)$

The Thiem equation is based on the assumption that flow is radial and that Darcian flow conditions occur through a horizontal, confined, “infinite"' homogeneous aquifer (Quinn et al. 2011). Due to the equation originally being developed for pumping tests in confined porous media aquifers whereby two observation boreholes are used, when using the equation for single-packer Lugeon tests in fractured rock, an uncertainty arises in the assumption of the radius of influence $\left(r_{o}\right)$. Royle (2002) and Yihdego (2017) both explain that a $r_{o}$ value of between $5 \mathrm{~m}$ and $10 \mathrm{~m}$ is reasonable and yields a realistic value for $K$, whilst Quinn et al. (2011) cites ranges from as small as 0.6 m (Zeigler 1976) to as large as $60 \mathrm{~m}$ (Maini 1972), but followed the example of Haimson and Doe (1983) by using $30 \mathrm{~m}$ for their $T$ calculations.

\subsection{Geotechnical centrifuge modelling of partially saturated systems}

A geotechnical centrifuge offers a powerful physical modelling technique that is capable of replicating gravitational dependent processes between a scaled model and prototype conditions (Phillips 1995; Taylor 1995). Geotechnical centrifuges are particularly useful to produce data that can be used to predict behaviour of a process that occurs naturally at a cumbersome spatial scale (Barry et al. 2001). This is done by accelerating a model an equivalent $N$ times Earth's gravitational field $g\left(\right.$ ca. $\left.9.81 \mathrm{~m} / \mathrm{s}^{2}\right)$ and results in the model being subjected to a centrifugal acceleration $N g$ (Jones et al. 2017b). The fundamental basis of geotechnical centrifuge modelling requires that the stress and strain conditions are identical between the laboratory model (the model scale) and to the problem under investigation (the prototype scale). To achieve similitude, the geometric, kinematic and dynamic properties can be scaled by selecting a rotational speed that induces an artificial gravity that is $N$ times stronger than Earths' gravity $(g)$ within the model compared to the prototype, ensuring a constant ratio between dimensions, forces, velocities and accelerations. 
There are numerous appropriate scaling laws that are used for centrifuge modelling, including for example (and discussed in detail by Culligan-Hensley and Savvidou, 1995; Jones et al., 2017b; Taylor 1995; Phillips, 1995; and Garnier et al., 2007):

- Linear dimensions;

- Stress;

- Time;

- Darcy's Law; and

- Reynolds Number.

Some of these scaling factors are summarized in Table 1. Particular to fracture flow, the ratio of body gravity to capillary forces must be correct in order to simulate fluid invasion in a fracture, and therefore the fracture aperture does not scale and is treated as a microscopic length (Culligan and Barry 1998). Adopting this reasoning however, the Capillary and Bond number's, which describe the interaction of gravitational, capillary and viscous forces, are not accurately represented (see Culligan and Barry 1998 for definition of these numbers). Notwithstanding, despite this failure, the Stokes number, which describes gravity driven flow instability, remains constant (Culligan and Barry 1998). Jones et al. (2017b) observed good accordance between flow mechanisms observed in a geotechnical centrifuge and previous research, which lead the authors to conclude that the geotechnical centrifuge replicates variably saturated flow mechanisms acceptably.

Table 1 Geotechnical centrifuge scaling factors (Culligan and Barry 1998; Garnier et al. 2007; Taylor 1995)

\begin{tabular}{|l|l|l|}
\hline Parameter & Symbol & Prototype/Model ratio \\
\hline Gravity & $g$ & $1 / N$ \\
\hline Macroscopic length (i.e. soil height) & $l$ & $N$ \\
\hline Microscopic length (i.e. fracture aperture) & $l$ & 1 \\
\hline Stress & $\sigma$ & 1 \\
\hline Strain & $\varepsilon$ & 1 \\
\hline Mass & $m$ & $N^{3}$ \\
\hline Force & $F$ & $N^{2}$ \\
\hline Dynamic viscosity & $\mu$ & 1 \\
\hline Intrinsic permeability & $\kappa$ & 1 \\
\hline Density & $\rho$ & 1 \\
\hline Seepage velocity & $v$ & $1 / N$ \\
\hline Time & $t$ & $N^{2}$ \\
\hline Reynolds number & $R_{e}$ & $1 / N$ \\
\hline
\end{tabular}


This is a postprint version of: Jones BR, Van Rooy JL, Dippenaar MA (2018) Lugeon Tests at Partial

Saturation: Experimental and Empirical Contributions. Rock Mechanics and Rock Engineering. http://dx.doi.org/10.1007/s00603-018-1592-0

\subsection{Research aims}

Considering the above rationale, the investigation of Lugeon-tests applied to unsaturated and fractured systems, specifically by isolating fundamental processes within an individual fracture, is therefore a significantly important research question in its own rights. This paper therefore addresses the rationale by aiming to incorporate:

1. Concepts of partially and variably saturated flow mechanisms in discrete fractures;

2. Available empirical and mathematical relationships and their applicability or relevance in describing partially saturated flow; and

3. Current understanding of the flow state or behaviour around a borehole for Lugeon tests, and how it may apply to the in-situ (field) scenario.

The above is conducted to correlate Lugeon test results, using the geotechnical centrifuge, with observed flow mechanisms within fractures. Existing empirical and mathematical approaches of relevance are used throughout the study in order to assess their applicability to the preferential conditions.

\section{MATERIALS AND METHODS}

The physical models tested in this study are developed by conceptualising a Lugeon test, using a single-packer, conducted within an interval of impermeable rock intersected by a single, discrete fracture at the base of the test section. In addition, the rock mass is located within the fractured vadose zone, such that unsaturated conditions are prevalent, and furthermore that the geometry of the fracture is simplified to the fundamental concept of the smooth parallel plate model, from which the cubic law is derived. Motivated by the results of Jones et al. (2017a), the first model consisted of a $1 \mathrm{~mm}$ aperture horizontal fracture, whilst a second model consisted of a fracture inclined at $23^{\circ}$ from the horizontal, and was modelled at both $1 \mathrm{~mm}$ and $0.50 \mathrm{~mm}$ apertures. The conceptualised field models alongside their appropriate centrifuge model is shown in Fig. 1. 


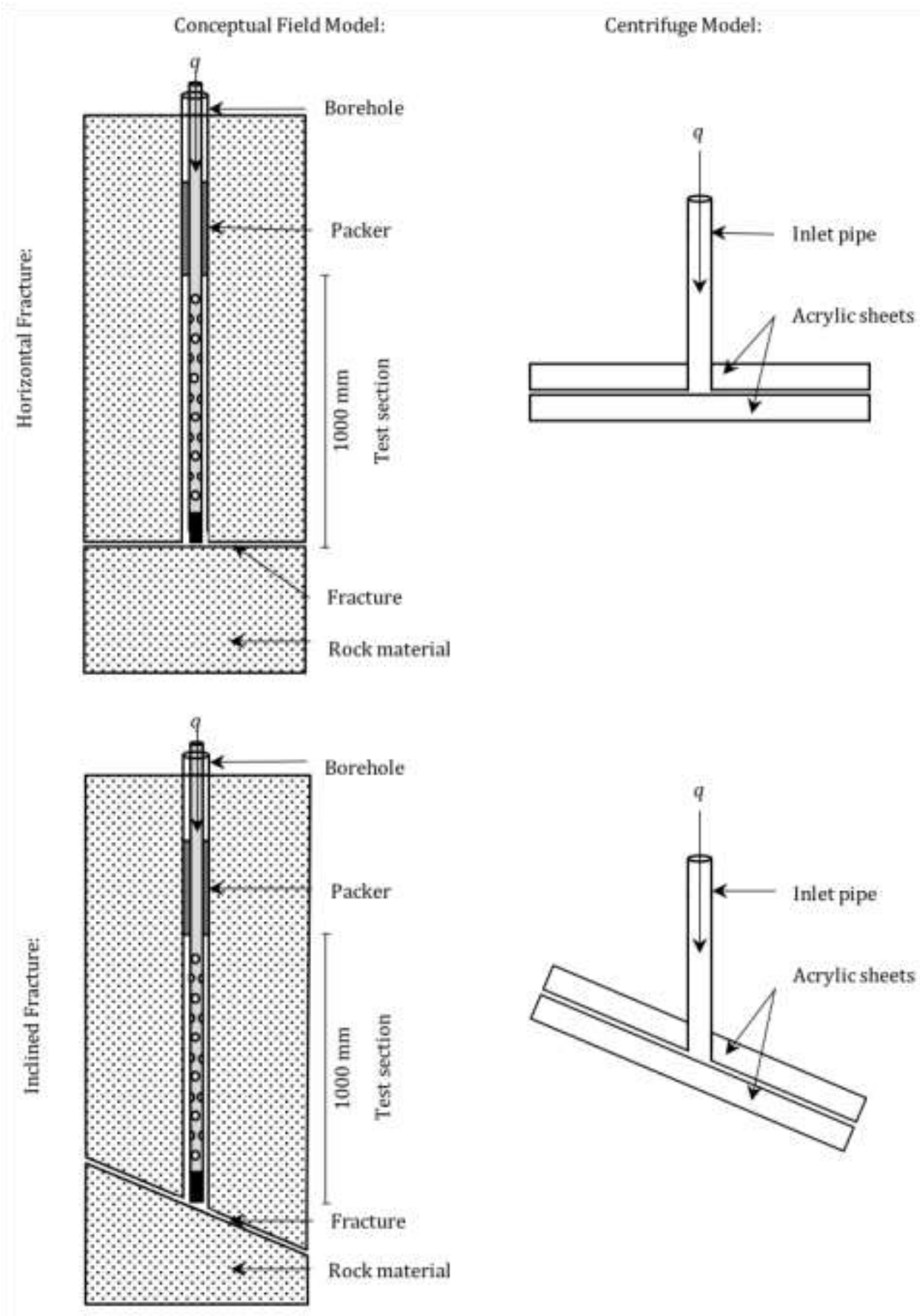

Fig. 1 Conceptualised field model showing a single borehole packer test over a $1 \mathrm{~m}$ length test interval that intersects a single discrete fracture at the base of the test section, with the accompanying centrifuge model that was used to simulate it

Within the centrifuge strongbox itself, where the model was constructed, the extent of the fracture is rectangular, with the long boundaries being discontinuous (i.e. terminating at this boundary), whilst being continuous along its short boundaries. As such, the fracture was open at the short boundaries such that flow could occur out of it, 
whilst fluid could not exit along the long boundaries. In order to simulate a radial borehole, the centrifuge model was constructed with an inlet pipe through the acrylic sheets, where the water was injected. The models are tested under multiple pressure steps as would be conducted for Lugeon tests conducted in the field (as described by e.g. Royle 2002; and Yihdego 2017).

Lugeon tests are typically conducted at high hydraulic pressures. However, previous literature has shown that the onset of non-Darcian flow occurs at relatively low flow rates for saturated conditions (e.g. Konzuk and Kueper 2004; Quinn et al. 2011; Ranjith and Darlington 2007; Zimmerman et al. 2004). Therefore, the Lugeon test stages conducted in this experimental study were conducted at low hydraulic pressures, relative to those generally used for Lugeon tests in the field. The set-up for the models and the procedure followed for each test is discussed in the following sections. The three geotechnical centrifuge model tests were performed at a scale of 1:20 using the 150 G-ton geotechnical centrifuge housed in the Department of Civil Engineering at the University of Pretoria. Details of the centrifuge facility are described by Jacobsz et al. (2014) and studies by Jones et al. (2017b), Van Tonder and Jacobsz (2017) and Brouwers and Dippenaar (2018) detail the verification of the applicability of this specific geotechnical centrifuge for partially saturated flow modelling.

\subsection{Test set-up}

\subsubsection{Horizontal fracture (Experiment 1)}

The horizontal model test (Experiment 1) consisted of 2 acrylic Plexiglas ${ }^{\mathrm{TM}}$ sheets measuring $400 \mathrm{~mm}$ length $\mathrm{x}$ $290 \mathrm{~mm}$ width $\times 10 \mathrm{~mm}$ thick, separated by spacers along both the long boundaries as well as 4 rectangular (20 $\mathrm{mm} \times 20 \mathrm{~mm}$ ) spacers within the fracture, in order to maintain a constant aperture of $1 \mathrm{~mm}$. As it was anticipated that the horizontal fracture would saturate more than the subsequent inclined fracture models, it was decided that 4 contact obstacles were sufficient in order not to influence flow behaviour due to the higher percentage of contact obstacles in the model fracture. Although the rectangular spacers are placed within the fracture to minimise bending of the acrylic sheets, possible change in aperture due to slight bending is duly noted as a possible influence on the study, particularly considering the accelerated conditions in the geotechnical centrifuge. An average contact angle for the acrylic sheets is reported as being approximately $70^{\circ}$ by Della Volpe et al. (2002), with the fracture being smooth at both the micro- and macroscopic level. Assuming saturated conditions, the fracture 
This is a postprint version of: Jones BR, Van Rooy JL, Dippenaar MA (2018) Lugeon Tests at Partial Saturation: Experimental and Empirical Contributions. Rock Mechanics and Rock Engineering. http://dx.doi.org/10.1007/s00603-018-1592-0

replica was therefore characterised by a hydraulic conductivity $\left(K_{f}\right)$ of $9.18 \times 10^{-1} \mathrm{~m} / \mathrm{s}$, and permeability $\left(k_{f}\right)$ of $8.33 \times 10^{-8} \mathrm{~m}^{2}$. The model set-up is illustrated in Fig. 2 .

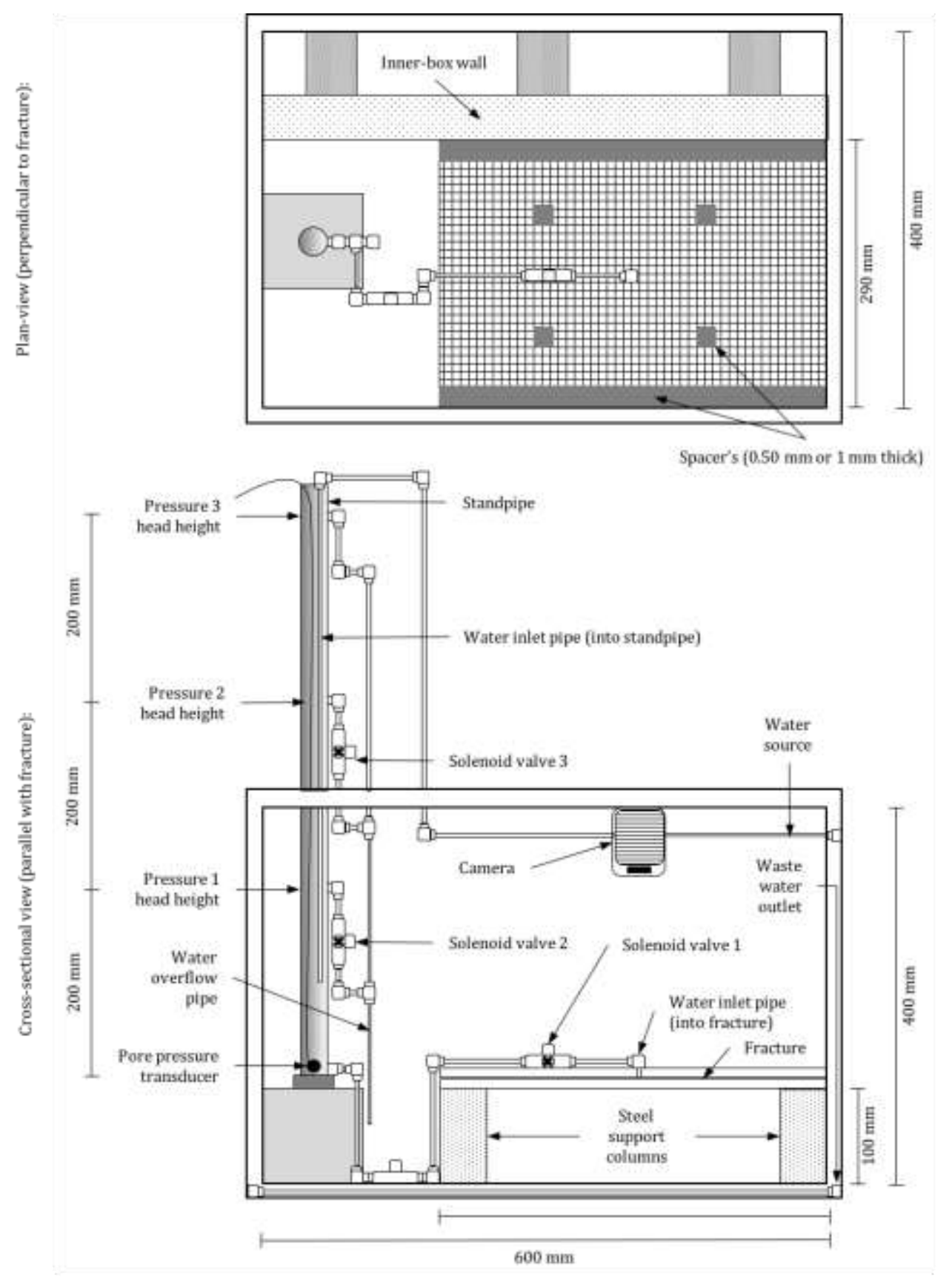

Fig. 2 Test set-up for the Lugeon test on the horizontal fracture (Experiment 1)

The inlet pipe (simulating the borehole) was positioned in the centre of the fracture. A grid was placed on the outside of the bottom acrylic sheet, facing inwards, in order to assess the geometry of the flow path. A standpipe was constructed with 3 overflow levels each at different heights, to test the model at 3 separate hydraulic pressures. 
These overflow levels were placed at heights of $200 \mathrm{~mm}, 400 \mathrm{~mm}$, and $600 \mathrm{~mm}$, respectively, above a pipe that connects to the fracture and was located at the bottom of the standpipe. This outlet pipe was placed at the same elevation as the inlet pipe into the fracture. A pore pressure transducer (PPT) was placed at the base of the standpipe to monitor the hydraulic pressure (hydraulic head) within the standpipe during each test. The water was introduced by a $4 \mathrm{~mm}$ inner diameter pipe that connected to the water source from the centrifuge platform, where the flow of water into the standpipe was controlled via a solenoid valve (electronic tap) located in the centrifuge control room. Potassium permanganate crystals were scattered at the base of the standpipe in order to colour the water that enters the standpipe. It was not possible to ensure that the potassium permanganate crystals would not influence the surface tension of the fluid used in the experiments. However, it was assumed that the addition of these minimal amounts of potassium permanganate would not influence the surface tension of the water and subsequently did not affect the results.

The pipe connected to the base of the standpipe was connected to the inlet source of the fracture via a pipe with an inner diameter of $4 \mathrm{~mm}$. The pipe was laid in the set-up such that it forms a u-bend to ensure it remained fully saturated during the test, and no air-locks develop within the system. Three solenoid valves (electronic taps) were placed in the model, with the first solenoid valve controlling the flow of fluid into the fracture. The second solenoid valve was placed directly below the lowermost overflow level $(200 \mathrm{~mm})$ such that it determines the hydraulic head when Pressure 1 as required, whilst the third solenoid valve controls the head height at the middle overflow level for Pressure 2. The valves are opened when a specific pressure interval is required, so that the water level could not rise higher than the required hydraulic pressure. Depending on when a specific hydraulic pressure was required, the corresponding solenoid valve was closed or opened such that the water level in the standpipe could rise or fall.

Each of the overflow levels were attached to an overflow pipe, which spilled the excess waste water into the centrifuge strongbox, and drained away thereafter. The inlet pipe to the fracture was connected to a drilled hole in the top of the acrylic sheet and fastened with epoxy and silicon to ensure that no leakage occurred. The water flow was monitored visually in flight by using the flow metre located in the centrifuge control room. A camera was placed on an overhead bracket above the horizontal fracture. 


\subsubsection{Inclined fracture's (Experiment 2 and Experiment 3)}

The inclined model test was performed on the same acrylic sheets (400 mm length x $290 \mathrm{~mm}$ width), set-up in a similar manner as the horizontal test, but placed on a concrete base inclined at $23^{\circ}$. The inlet pipe for the fluid source was positioned $300 \mathrm{~mm}$ above the bottom of the upper acrylic sheet. The model was tested at 2 apertures, namely, $1 \mathrm{~mm}$ (Experiment 2) and $0.5 \mathrm{~mm}$ (Experiment 3) respectively. Both apertures were maintained by spacer's that ran down the long-boundary of the fracture, with 6 rectangular spacers' $(20 \mathrm{~mm} \times 20 \mathrm{~mm})$ placed within the fracture in order to mitigate bending of the acrylic sheet, although possible change in aperture due to bending is noted as an influence on the results of the model. As the same acrylic sheets are used, a similar contact angle is considered for the inclined experimental set up (ca. $70^{\circ}$ ). The model set-up is illustrated in Fig. 3 .

Assuming saturated conditions, the fracture replica of the $1 \mathrm{~mm}$ model was therefore characterised by a hydraulic conductivity $\left(K_{f}\right)$ of $9.18 \times 10^{-1} \mathrm{~m} / \mathrm{s}$, and permeability $\left(k_{f}\right)$ of $8.33 \times 10^{-8} \mathrm{~m}^{2}$, whilst the $0.50 \mathrm{~mm}$ model exhibited a hydraulic conductivity $\left(K_{f}\right)$ of $2.30 \times 10^{-1} \mathrm{~m} / \mathrm{s}$, and permeability $\left(k_{f}\right)$ of $2.08 \times 10^{-8} \mathrm{~m}^{2}$. A grid was placed on the outside of the opposite Plexiglass sheet, facing inwards, so that the geometry of the flow paths could be assessed. The same standpipe with the three overflow levels was used, as was in the horizontal fracture model. The overflow levels were placed $200 \mathrm{~mm}, 400 \mathrm{~mm}$, and $600 \mathrm{~mm}$, respectively, above the base of the standpipe. The base of the standpipe was located at the same elevation as the inlet pipe into the fracture. A pore pressure transducer (PPT) was placed at the base of the standpipe monitor the hydraulic pressure (hydraulic head).

The lower outlet valve was also attached at the bottom of the standpipe which fed into a u-bend, ensuring that the pipe remained fully saturated during the test. Three solenoid valves were placed in the model, and were again opened or closed depending on what hydraulic head was required for each pressure interval. Water influx was also monitored in flight by a flow metre in the centrifuge control room. A camera was placed on an overhead bracket above the horizontal fracture. 
This is a postprint version of: Jones BR, Van Rooy JL, Dippenaar MA (2018) Lugeon Tests at Partial Saturation: Experimental and Empirical Contributions. Rock Mechanics and Rock Engineering. http://dx.doi.org/10.1007/s00603-018-1592-0

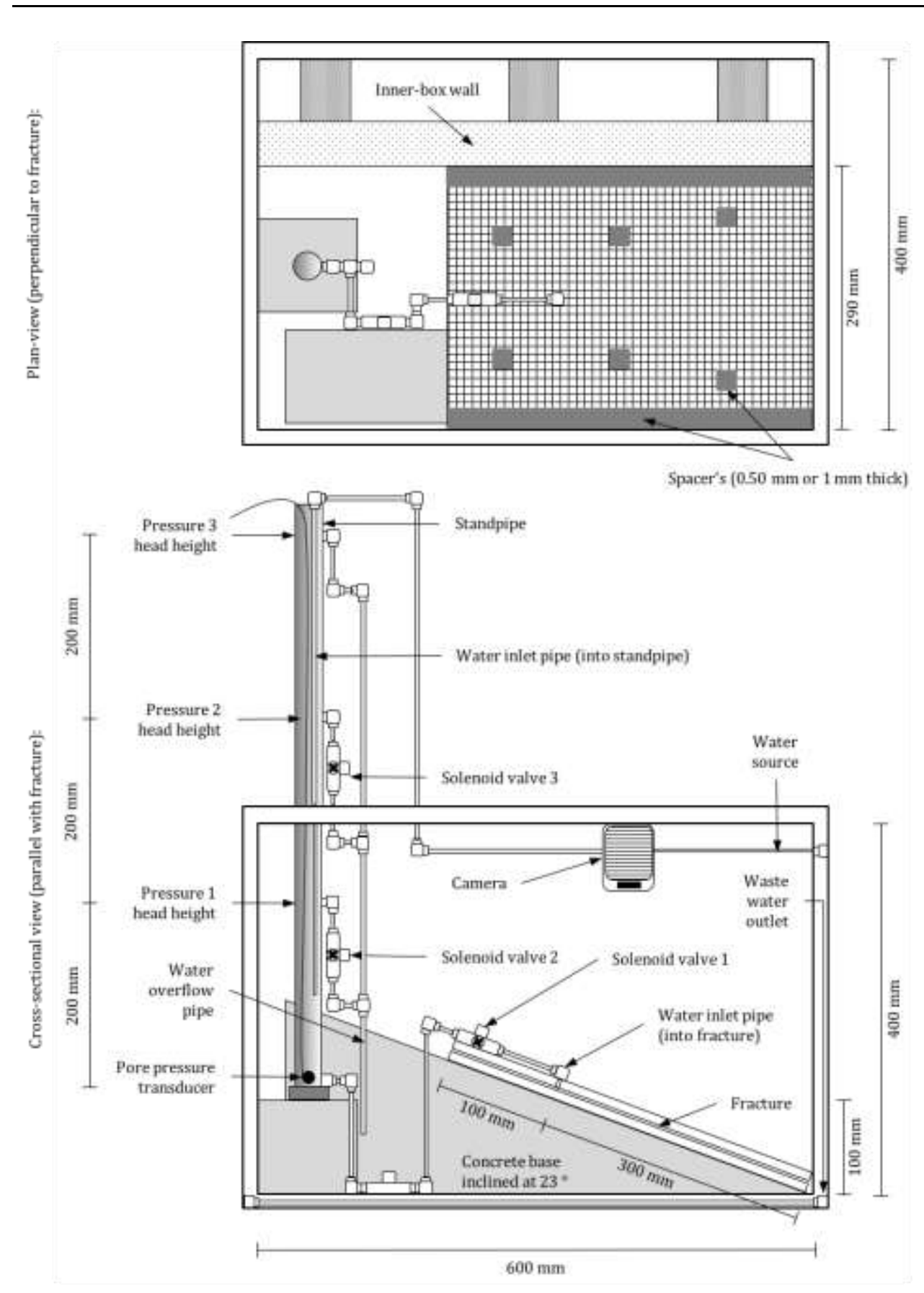

Fig. 3 Test set-up for the Lugeon test on the inclined fracture's (Experiment 2 and Experiment 3)

\subsection{Test procedure}

Three tests were conducted at 20G, namely, on i) the horizontal $1 \mathrm{~mm}$ aperture fracture model (Experiment 1), ii) the inclined $1 \mathrm{~mm}$ aperture fracture model (Experiment 2), and iii) the inclined $0.5 \mathrm{~mm}$ aperture fracture model (Experiment 3). Once the completed model was accelerated to the desired G-level, it was tested under multiplepressures, consisting of 5 pressure steps in a series of ascending and descending intervals. The pressure recorded 
by the PPT at the base of the standpipe was used to monitor the required hydraulic pressure for each step. Each step was conducted until a constant head is achieved in the standpipe at the required pressure, whilst the constant flow rate being achieved during this constant head was recorded.

The hydraulic pressures at the base of the standpipe for the respective overflow levels are summarised in Table 2 . However, as there was a $200 \mathrm{~mm}$ horizontal distance between the base of the standpipe and inlet pipe into the fracture, the corresponding hydraulic gradient resulted in the hydraulic pressures at the inlet into the fracture being less than those recorded in the standpipe. Therefore, these pressures were reduced in order to account for this loss of hydraulic pressure along the hydraulic gradient, which therefore resulted in lower imposed hydraulic pressure intervals for the tests (i.e. at the fracture inlet) at each overflow levels in the standpipe. The imposed hydraulic pressures for each respective pressure step is also included in Table 2. Any frictional losses through the pipe that delivers the fluid from the standpipe to the model was assumed as negligible. An example of the data obtained from this pore pressure is shown in Fig. 4 for the inclined $1 \mathrm{~mm}$ fracture model (Experiment 2).

Table 2 Summary of hydraulic pressures at each pressure step imposed on the models

\begin{tabular}{|c|c|c|c|}
\hline \multirow{2}{*}{ Pressure Step } & \multicolumn{2}{|c|}{ Standpipe } & \multirow{2}{*}{$\begin{array}{c}\text { Imposed hydraulic pressure at } \\
\text { fracture inlet }(\mathrm{kPa})\end{array}$} \\
\cline { 2 - 3 } & Overflow level height $(\mathrm{mm})$ & Hydraulic pressure $(\mathrm{kPa})$ & 18.9 \\
\hline Pressure 1 & 200 & 39.24 & 33.5 \\
\hline Pressure 2 & 400 & 78.48 & 51.7 \\
\hline Pressure 3 & 600 & 117.72 & \\
\hline
\end{tabular}


This is a postprint version of: Jones BR, Van Rooy JL, Dippenaar MA (2018) Lugeon Tests at Partial Saturation: Experimental and Empirical Contributions. Rock Mechanics and Rock Engineering.

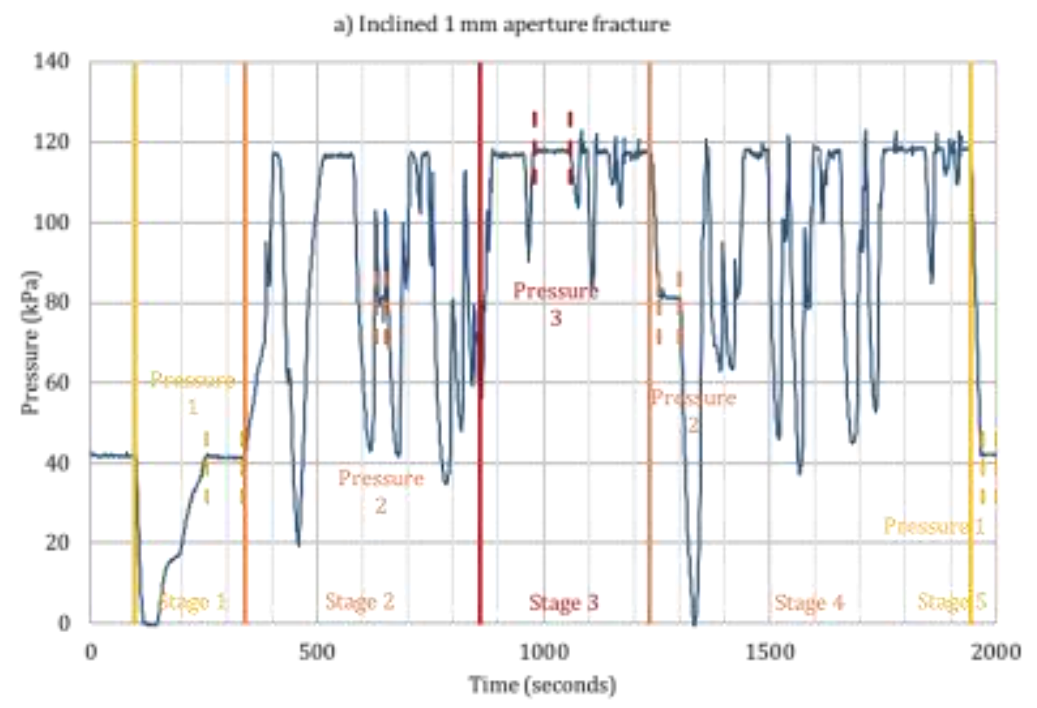

b) Experiment 2: Indined 1 mm aperture fracture
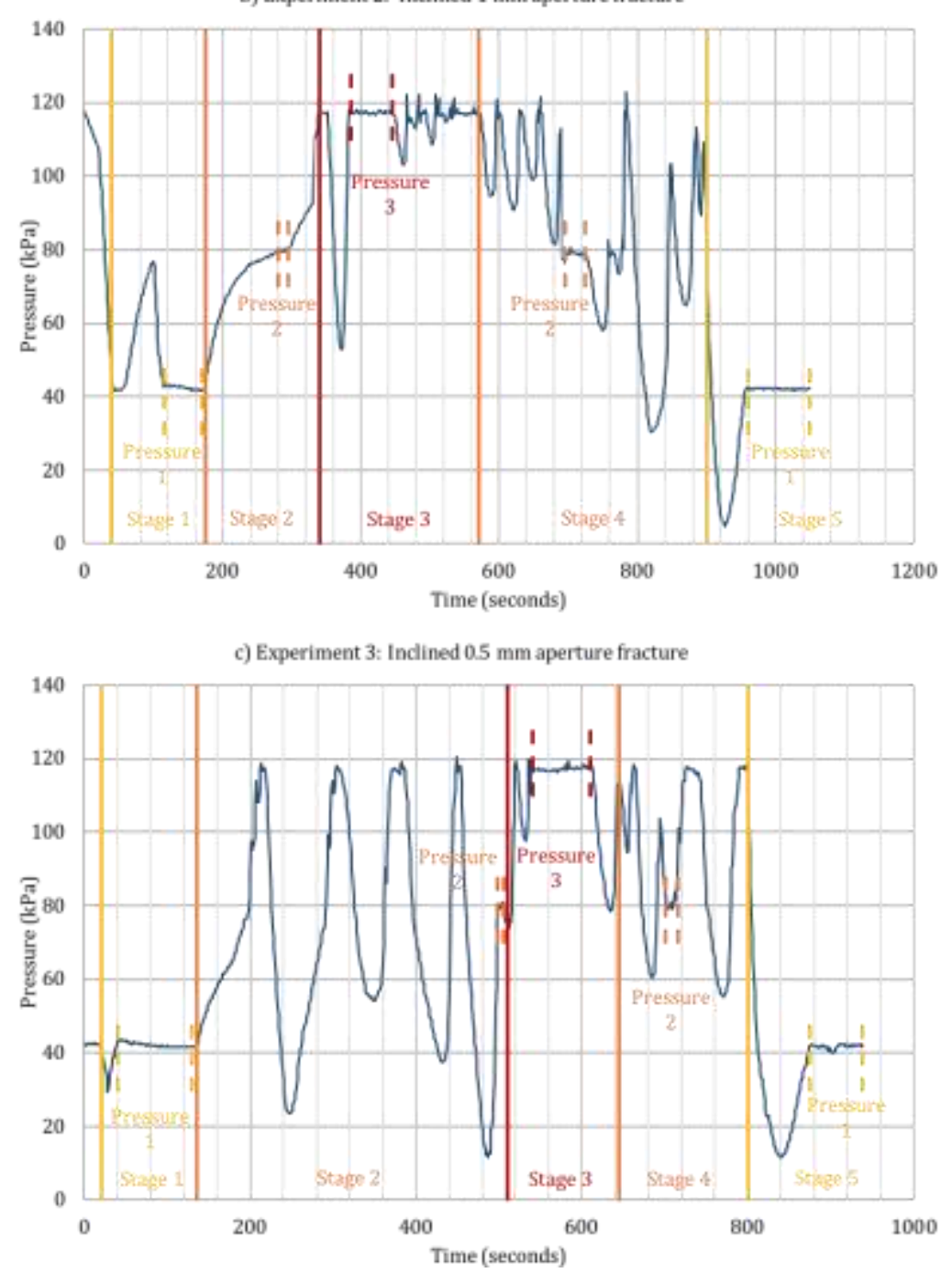

Fig. 4 Data obtained from the pore pressure transducer (PPT) at the base of the standpipe. Flow rates were measured when constant head conditions were achieved at each stage (i.e. between the dotted lines) 
Before initiation of the test, solenoid valve 1 was closed, whilst solenoid valve 2 and 3 remained open, and fluid was added to the standpipe via the water source pipe by opening the tap in the centrifuge control room. Upon initiating the test, solenoid valve 1 was opened which allowed the fluid to enter the fracture. In the centrifuge control room, the flow rate delivered to the model was monitored by a flow meter attached to the water source tap, whilst the hydraulic pressure in the standpipe was monitored in-flight by a data acquisition system attached to the PPT. This resulted in water being added to the standpipe, with the water level rising to the first overflow height at $200 \mathrm{~mm}$ (Pressure 1), where any waste-water was discarded through the overflow pipe.

The flow rate into the standpipe was adjusted until equilibrium was achieved between the flow being delivered and the required constant hydraulic head for the first pressure step. Once equilibrium was achieved, during Stage 1 at Pressure $1(18.9 \mathrm{kPa})$, the flow rate was recorded and solenoid valve 2 was closed such that the hydraulic head increases to Pressure $2(33.5 \mathrm{kPa})$ for Stage 2 of the test. Once again, the water influx was managed at the control room until a constant flow was obtained and recorded. When constant head conditions were achieved and the flow rate recorded at Pressure 2 during Stage 2, solenoid 3 was closed and the water level rises to the constant head required Pressure $3(51.6 \mathrm{kPa})$, such that Stage 3 of the test commences. Similarly, the flow rate was recorded once equilibrium (constant flow rate at a constant head) was achieved. For the subsequent stages, solenoid valve 3 was reopened, initiating the series of decreasing pressure steps, whereby the water level dropped back to Pressure $2(33.5 \mathrm{kPa})$ for Stage 4, and the flow rate was recorded at a constant head conditions in order to ensure similarity to the rate achieved in the corresponding ascending step. Once recorded, solenoid 2 is reopened so that the water level dropped back to Pressure $1(18.9 \mathrm{kPa})$ for Stage 5, with the flow rate being recorded again at constant head conditions. Once the flow rates were recorded for all stages (ascending and descending pressure intervals), the test is stopped.

\section{CENTRIFUGE MODELLING TEST RESULTS}

\subsection{Experiment 1: Horizontal $1 \mathrm{~mm}$ aperture fracture}

At the initiation of Stage 1 into the test, the hydraulic head rapidly decreased in the standpipe as fluid entered the fracture, causing a deficit water balance in the standpipe. The invasion of fluid from the inlet occurred as an advancing finger of fluid within the first second of the interval, and thereafter this finger established as a horizontal rivulet. Within the first 2 seconds, 3 additional rivulets had extended towards the long boundaries of the fracture 
where the fluid ponded against the spacers, and moved laterally towards the short boundaries of the fracture, where it exited. Some of the major flow paths meandered and oscillated, which is indicative that the flux rate within these rivulets was high (from the resulting boundary between inertial, viscous, capillarity and gravitational forces). The observed flow behaviour for each stage is shown in Fig. 5. As surplus water was added to the standpipe, the hydraulic head reached the required level at 160 seconds (17.8 hours) for the flow rate at Pressure $1(18.9 \mathrm{kPa})$ to be recorded. Once reached, Pressure 1 was maintained for 85 seconds (9.44 hours) where a constant flow rate of $0.67 \mathrm{l} / \mathrm{min}(13.4 \mathrm{l} / \mathrm{min})$ was recorded. Italicised values in parentheses refer to the full prototype scale values (e.g. time, volumetric flow rate, linear dimensions, etc.).

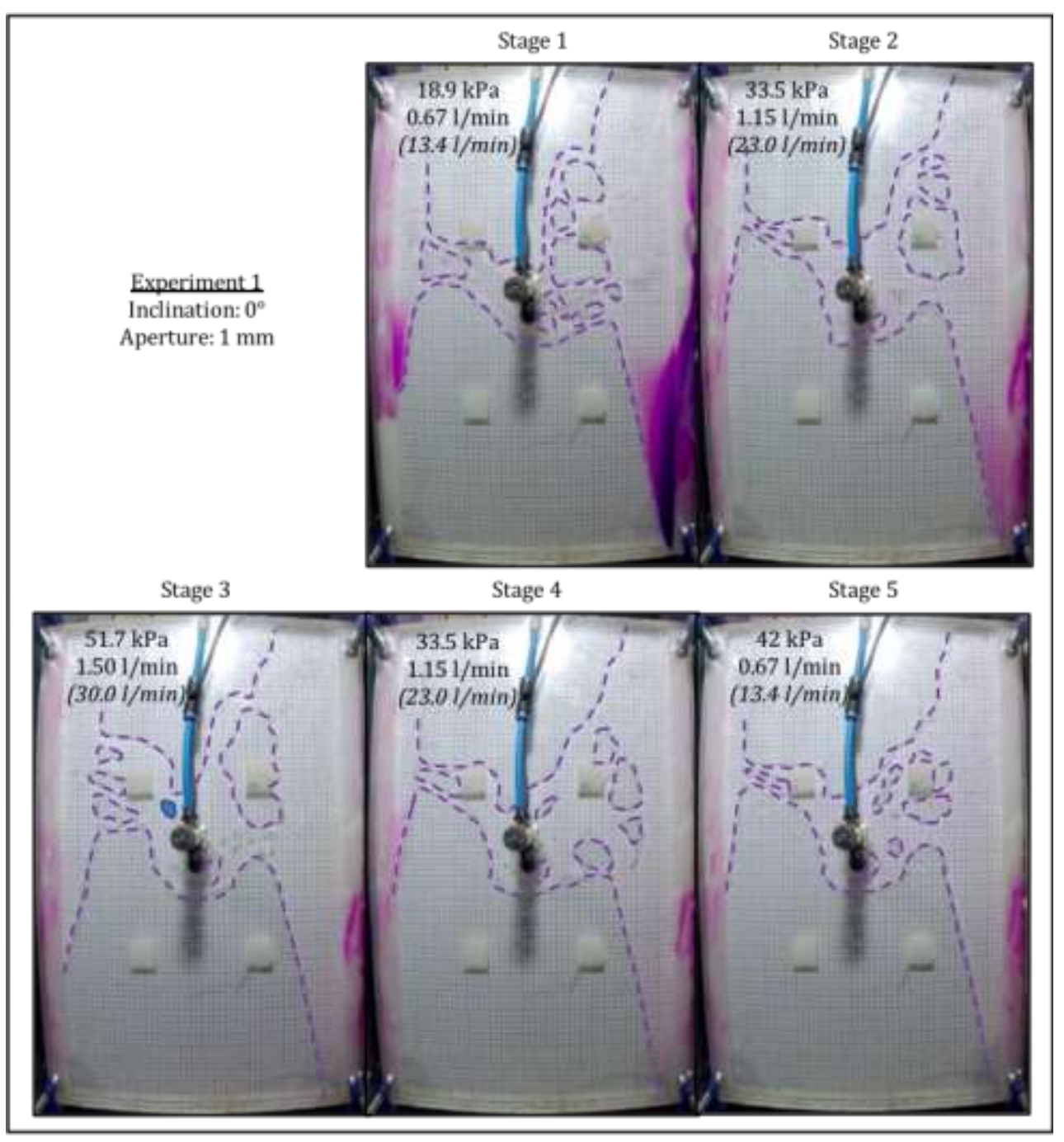

Fig. 5 Flow behaviour during each stage of Experiment 1 (dotted lines indicate flow path (rivulets) boundaries; italicised values in parentheses refer to prototype scale) 
Stage 2 was initiated at 305 seconds (33.9 hours) into the test. However, cavitation that occurred in the water source pipe that fed water into the standpipe resulted in difficulty in obtaining the constant head required for this pressure interval. Nevertheless, Pressure $2(33.5 \mathrm{kPa})$ was obtained for 20 seconds $(2.2$ hours $)$ where a constant flow rate of $1.15 \mathrm{l} / \mathrm{min}(23 \mathrm{l} / \mathrm{min})$ was recorded flowing into the fracture. Stage 3 is started 765 seconds $(85$ hours $)$ into the test, with a flow rate of $1.50 \mathrm{l} / \mathrm{min}(30.0 \mathrm{l} / \mathrm{min})$ being recorded when the required constant head $(51.6 \mathrm{kPa})$ was achieved for 80 seconds ( 8.89 hours) at 885 seconds $(98.3$ hours) into the test. During the subsequent descending stages, similar flow rates confirmed those recorded during the ascending stages at the same pressures. When there was a deficit of flow into the standpipe and the water level decreased, cavitation occurred and the rivulets within the fracture diminished, resulting in some flow paths disappearing with static droplets remaining along the extinct flow paths. When the water level in the standpipe recovered, and fluid reinvaded the fracture, flow re-established along these extinct paths, which was likely a function of their favourable wettability.

The tendency for the flow paths to meander circularly outwards from the inlet and towards the spacers along the length of the fracture, was due to a combination of the position of the maximum centrifugal force acting perpendicular at the centre of the fracture (i.e. centrifugal force becomes decreasingly less than 20G further from this axis), coupled with the large capillary barrier that was present at the short unconfined boundaries of the fracture. Furthermore, the rectangular spacers within the fracture also acted to dictate the positions of these flow paths due to their inherent capillarity (and the ensuing hysteric behaviour). It is assumed that all rivulets were aperture-spanning, based on the sharp meniscus that formed, and was identified by the reflection of light off the edges of the rivulets.

Despite the rivulets forming liquid bridges across the aperture of the fracture $(1 \mathrm{~mm})$, the fracture area (perpendicular to the fracture) did not saturate during the experiment, and flow occurs preferentially. In this regard, the percentage area of the fracture $(290 \times 400 \mathrm{~mm}-5.8 \mathrm{~m} \times 8 \mathrm{~m})$ that saturated (area perpendicular to the fracture) during Pressure 1 is approximately 28\%, increasing to $31 \%$ at Pressure 2, and then to $40 \%$ during Pressure 3. There was clearly a gradual increase in the saturation adjacent to the inlet upon each increasing pressure interval; however, increases in the saturation was more noticeable in the fluid fingers farther from the inlet. This gradual increase in saturation at higher pressures was not constant across all fluid fingers, where instead some flow paths were narrower from one interval to the next, others were often wider. 


\subsection{Experiment 2: Inclined $1 \mathrm{~mm}$ aperture fracture}

As Stage 1 was initiated, the hydraulic head rapidly increased as an excess amount of water was delivered to the standpipe. Fluid entered the fracture as a single wide rivulet that flows down the inclination of the fracture, establishing along its length within 1 second $(6.67$ mins $)$. During Stage 1, the maximum width of the flow path was approximately $40 \mathrm{~mm}(800 \mathrm{~mm})$ wide. Between $75(8.3$ hours $)$ and 130 seconds $(14.4$ hours $)$ into the test, a constant flow rate of $0.67 \mathrm{l} / \mathrm{min}(13.4 \mathrm{l} / \mathrm{min})$ was recorded at the constant head achieved at Pressure $1(18.9 \mathrm{kPa})$. The observed flow behaviour for each stage is shown in Fig. 6. Stage 2 commences at 135 seconds (15.0 hours) into the test, and the hydraulic head gradually rised to the constant head required at Pressure $2(33.5 \mathrm{kPa})$. A constant flow rate of $1.15 \mathrm{l} / \mathrm{min}(23.0 \mathrm{l} / \mathrm{min})$ was achieved for 15 seconds ( 1.6 hours $)$ during Stage 2 at the constant head for Pressure 2. The flow path increased to a width of $50 \mathrm{~mm}(1.0 \mathrm{~m})$ during this Stage 2. A constant flow rate of $1.46 \mathrm{l} / \mathrm{min}(29.2 \mathrm{l} / \mathrm{min})$ was recorded at 345 seconds (38.3 hours) during Stage 3 when a constant head was achieved at Pressure $3(51.73 \mathrm{kPa})$. The width of the flow path increased slightly to $55 \mathrm{~mm}(1.1 \mathrm{~m})$ during Stage 3. The wide rivulet that established within the fracture exhibits a wavy surface. During the subsequent descending stages, similar flow rates confirmed those recorded during the ascending stages at the same pressures.

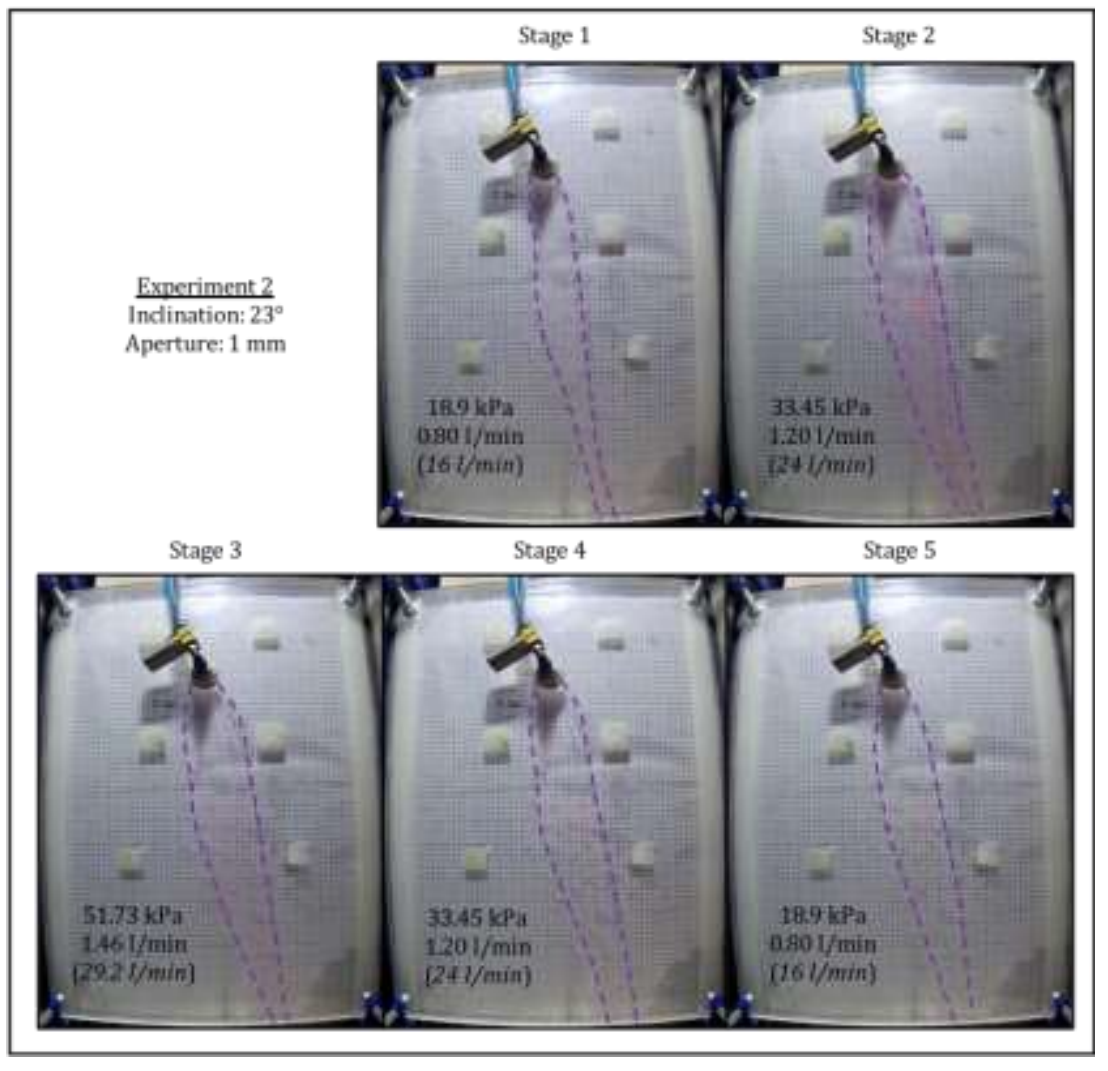

Fig. 6 Flow behaviour during each stage of Experiment 2 (dotted lines indicate flow path (rivulet) boundaries; italicised values in parentheses refer to prototype scale) 
The dimensions of the flow path was characterised by no noticeable increase in the saturation adjacent to the inlet during the increasing and decreasing pressure intervals. This cross-sectional width within the fracture (area parallel with fracture) directly adjacent to the inlet (borehole) remained the same at approximately $17 \mathrm{~mm}$ (340 $\mathrm{mm}$ ). It was likely that upon increasing the pressure, the width of saturation increased, but this was likely not seen at the qualitative resolution of the camera and grid that was used. However, farther from the inlet, it is clear that the width of the flow path increases markedly upon the increasing pressure intervals. Here, the flow path attained its maximum width at $60 \mathrm{~mm}(1.2 \mathrm{~m})$ down-dip of the inlet along the flow path, and increased from $35 \mathrm{~mm}$ at Stage 1 to $55 \mathrm{~mm}$ at Stage 3. Further along the flow path, the width pinched and became increasingly narrower towards the fracture exit, at its lower short boundary. Based on the flow of fluid from the inlet, fluid likely flowed up-dip of the inlet, but was mostly concealed by the opaque sealant surrounding it. This saturation that occurs up-dip of the inlet was therefore assumed to be a maximum of $10 \mathrm{~mm}(200 \mathrm{~mm})$. Overall, the percentage area (area perpendicular to fracture) of the fracture that saturates during Pressure 1 is approximately $11 \%$, increasing slightly to $13 \%$ at Pressure 2, and at the highest imposed hydraulic head (Pressure 3) the degree of saturation had only increased to approximately only $14 \%$.

\subsection{Experiment 3: Inclined $0.5 \mathrm{~mm}$ aperture fracture}

The hydraulic head decreased as fluid entered the fracture during the initiation of Stage 1, causing a deficit water balance in the standpipe. Fluid entered the fracture as a single wide rivulet that flowed down the inclination of the fracture, establishing along its length within 1 second (6.67 mins). During Stage 1, the maximum width of the flow path was approximately $50 \mathrm{~mm}(1.0 \mathrm{~m})$ wide. The observed flow behaviour for each stage is shown in Fig. 7. During Stage 1, between 20 (2.2 hours) and 110 seconds (12.2 hours) into the test a constant flow rate of 0.63 1/min $(12.6 \mathrm{l} / \mathrm{min})$ was recorded at the constant head achieved at Pressure $1(18.9 \mathrm{kPa})$. 
This is a postprint version of: Jones BR, Van Rooy JL, Dippenaar MA (2018) Lugeon Tests at Partial

Saturation: Experimental and Empirical Contributions. Rock Mechanics and Rock Engineering. http://dx.doi.org/10.1007/s00603-018-1592-0

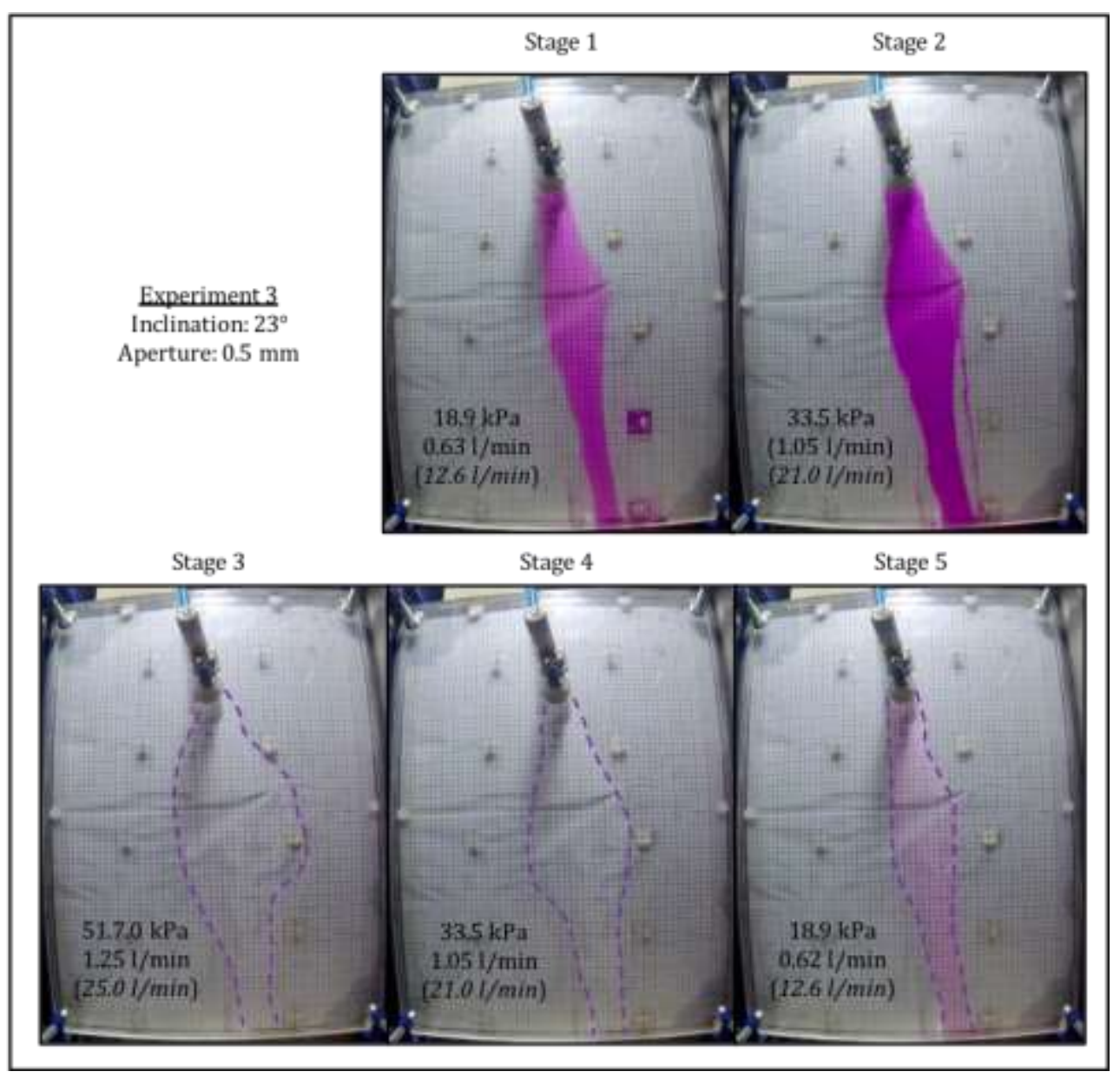

Fig. 7 Flow behaviour during each stage of Experiment 3 (dotted lines indicate flow path (rivulets) boundaries; italicised values in parentheses refer to prototype scale)

Stage 2 commenced at 115 seconds (12.8 hours) into the test; however, due to cavitation in the water source pipe from the centrifuge platform it was difficult to achieve constant flow under the required constant head. Nevertheless, a constant flow rate of $1.05 \mathrm{l} / \mathrm{min}(21.0 \mathrm{l} / \mathrm{min})$ was achieved for 7 seconds (46 minutes) towards the end of Stage 2 at the constant head for Pressure $2(33.5 \mathrm{kPa})$. The flow path increased to a width of $65 \mathrm{~mm}(1.3$ $m$ ) during Stage 2. A constant flow rate was achieved at 520 seconds (57.8 hours) during Stage 3 when a constant head was achieved at Pressure $3(51.73 \mathrm{kPa})$. The maximum width of the flow path increased to approximately $110 \mathrm{~mm}(2.2 \mathrm{~m})$ during Stage 3. During the subsequent descending stages, similar flow rates confirmed those recorded during the ascending stages at the same pressures.

Throughout the increasing and decreasing pressure intervals, the dimensions of the flow path were characterised by no noticeable increase in the saturation adjacent to the inlet, and remained the same at approximately $70 \mathrm{~mm}$ 
$(1.40 \mathrm{~m})$. Once again, although possible widening did occur, this was not observable at the test resolution, which was dictated by qualitative nature of the camera and grid. The saturation up-dip was also assumed to be no more than $10 \mathrm{~mm}(200 \mathrm{~mm})$ as it was mostly obscured by the sealant around the inlet. The flow path farther from the inlet markedly increased in width at higher pressures. Here, the flow path attains a maximum width $130 \mathrm{~mm}(2.6$ $m$ ) down-dip of the inlet along the flow path, and increased from $50 \mathrm{~mm}$ at Stage 1 to $110 \mathrm{~mm}$ wide by Stage 3 . Further along the flow path, this width again pinched and became increasingly narrower towards the fracture exit, at its lower short boundary. The overall percentage area of saturation (area perpendicular to the fracture) during Pressure 1 was approximately $11 \%$, increasing slightly to $13 \%$ at Pressure 2 , and at the highest imposed hydraulic head (Pressure 3) the percentage saturation had only increased to approximately $20 \%$.

\section{RESULTS AND DISCUSSION}

\subsection{Lugeon $(\mathrm{Lu})$ values}

Assuming the length of the test interval, $L$, was assumed to be $1 \mathrm{~m}$ at prototype scale ( $50 \mathrm{~mm}$ in model dimensions) for the tests (i.e. 1 fracture intersects the $1 \mathrm{~m}$ test interval), the recorded flow rates (at prototype scale) are used to calculate the $L u$-number for each step by Eq. 5, with the calculated $L u$-number per pressure interval for each test is shown in Fig. 8. When inspecting the calculated $L u$-number for each pressure step, the value calculated for the peak pressure at Stage $3(51.7 \mathrm{kPa})$ is less than those for the two medium-pressures (Stage 2 and 4$)$ at $33.5 \mathrm{kPa}$, as well as those for the low-pressure Stages (1 and 5) at $18.9 \mathrm{kPa}$. This suggests that all experiments display turbulent flow behaviour patterns. In this regard, the appropriate $L u$-value is taken at the highest pressure (51.7 $\mathrm{kPa}$ ) at Stage 3. Therefore, the reported $\mathrm{Lu}$-value for Experiment 1 (horizontal $1 \mathrm{~mm}$ aperture fracture) is 591, whilst for Experiment 2 (inclined $1 \mathrm{~mm}$ aperture fracture) the $L u$-value is 576, with Experiment 3 (inclined 0.50 $\mathrm{mm}$ aperture fracture) recording the lowest $L u$-value of 493 . These might appear unrealistically high, but considering the nature of the idealised smooth, parallel, clean, open fracture that was tested, the resulting high hydraulic conductivity should be represented by excessively high Lugeon-value's, respective to typical values obtained during field investigations. 
This is a postprint version of: Jones BR, Van Rooy JL, Dippenaar MA (2018) Lugeon Tests at Partial Saturation: Experimental and Empirical Contributions. Rock Mechanics and Rock Engineering. http://dx.doi.org/10.1007/s00603-018-1592-0

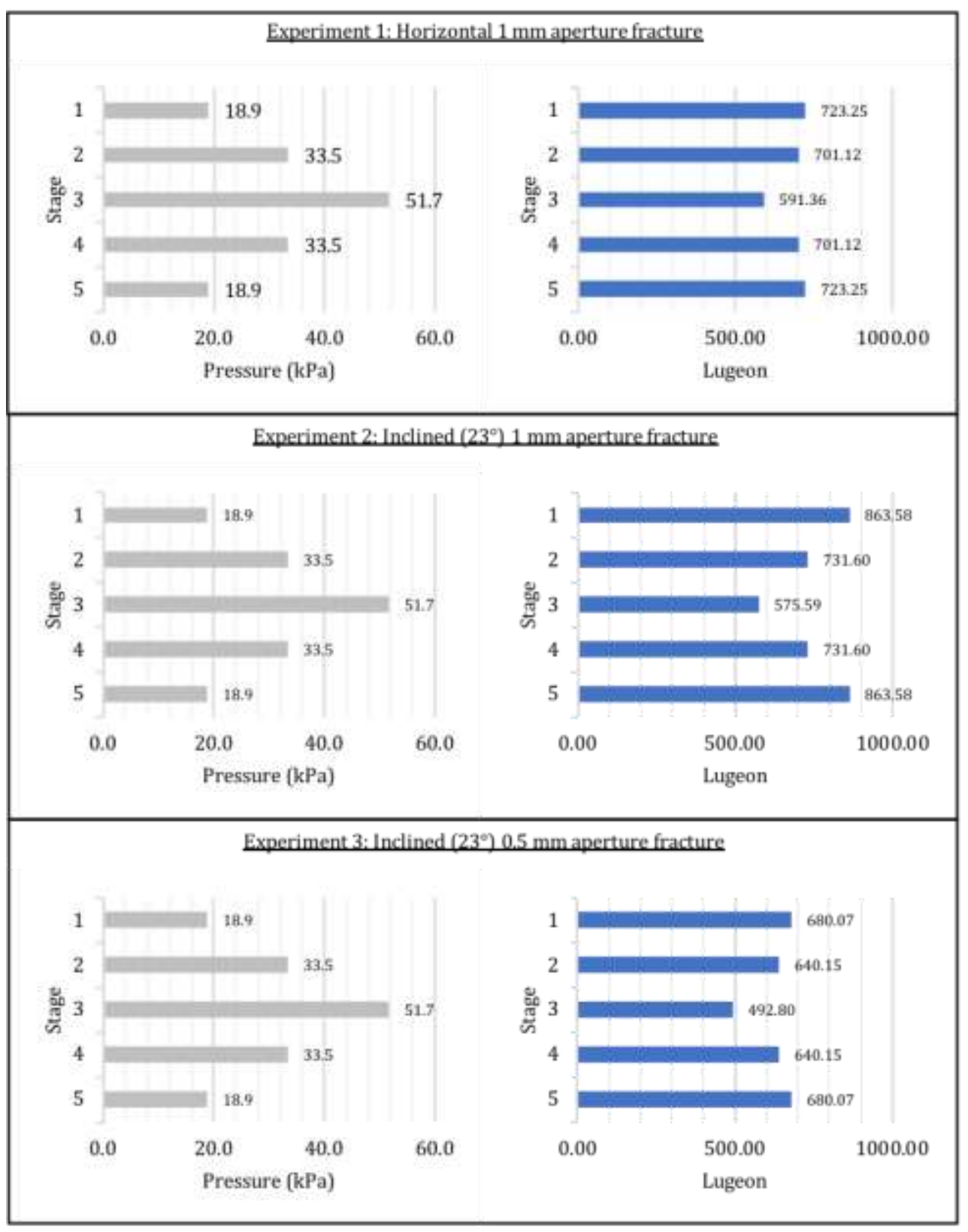

Fig. 8 Pressures and corresponding Lugeon numbers for each stage during each experiment

Although each experiment showed turbulent flow patterns, the most prominent turbulent pattern is seen in Experiment 2 (inclined $1 \mathrm{~mm}$ aperture). In this model, there is a noticeable decrease in the $L u$-number as the pressure increases. In comparison, the tests conducted on Experiment 1 (horizontal $1 \mathrm{~mm}$ aperture fracture), and Experiment 3 (inclined $0.5 \mathrm{~mm}$ aperture fracture) are less prominent. In both of these tests, the decrease in the $L u$-number between the lowest (18.9 kPa during Stage 1 and 5) pressure and the middle pressure (33.5 kPa during Stage 2 and 4) is not as significant as that recorded during Experiment 2 (inclined $1 \mathrm{~mm}$ aperture). This likely indicates differing onsets of non-linear flow (laminar to turbulent), whereby this point occurs at the highest- 
pressure interval (Stage 3) for Experiment 1 and Experiment 3. This observation is likely due to the stabilisation of fluid flow due to the increased saturation in the horizontal Experiment 1 (and associated tendency to simpler single-phase flow conditions), and the smaller aperture of the inclined Experiment 3, respectively. Furthermore, results show that calculated $L u$-values for the $1 \mathrm{~mm}$ aperture fractures (Experiment 1 and Experiment 2) are similar. In comparison, the $L u$-value for Experiment 3 is lower, and this phenomenon is associated with the smaller aperture that results in a lower hydraulic conductivity.

\subsection{Pressure-Flux $(P Q)$ relationships}

The recorded pressures (expressed in $\mathrm{mH}_{2} 0$ ) at prototype scale, versus the recorded fluxes (expressed in $\mathrm{m}^{3} / \mathrm{sec}$ ) at prototype scale are constructed for all experiments and are presented in Fig. 9.

The diagrams largely reiterate the observations of the $L u$-numbers, and show a gradual non-linear relationship during each of the experiments. Comparison of Experiment 1 and 2 (1 mm aperture fractures) show that similar fluxes $(Q)$ are observed for the second $\left(3.35 \mathrm{mH}_{2} 0\right)$ and third $\left(5.17 \mathrm{mH}_{2} 0\right)$ hydraulic heads. The fluxes at these respective hydraulic heads are $3.38 \times 10^{-4} \mathrm{~m}^{3} / \mathrm{sec}$ and $5.0 \times 10^{-4} \mathrm{~m}^{3} / \mathrm{sec}$ for Experiment 1 , and $4.0 \times 10^{-4} \mathrm{~m}^{3} / \mathrm{sec}$ and $4.9 \times 10^{-4} \mathrm{~m}^{3} / \mathrm{sec}$ for Experiment 2. Conversely, different fluxes are recorded at the lowest hydraulic head of $1.89 \mathrm{mH}_{2} 0$; whereby, during the lowest imposed hydraulic head $\left(1.89 \mathrm{mH}_{2} 0\right)$, a flux of $2.21 \times 10^{-4} \mathrm{~m}^{3} / \mathrm{sec}$ is recorded in Experiment 1, whilst in Experiment 2 a flux of $2.65 \times 10^{-4} \mathrm{~m}^{3} / \mathrm{sec}$ is recorded. This results in different points on the graph where linear flow ceases, and non-linear flow behaviour begins. In Experiment 1, this point occurs closer to the second hydraulic head $\left(3.35 \mathrm{mH}_{2} 0\right)$, whilst the non-linear behaviour gradually begins occurring after the first hydraulic head interval $\left(1.89 \mathrm{mH}_{2} 0\right)$ in Experiment 2. The observation of a linear relationship occurring at higher hydraulic heads in Experiment 1 is likely due to the higher degree of saturation in the fracture, between the first and subsequent hydraulic heads. The observation of this difference, between horizontal and inclined experiments, is indicative of the importance that the fracture orientation has on non-linear behaviour. 
This is a postprint version of: Jones BR, Van Rooy JL, Dippenaar MA (2018) Lugeon Tests at Partial Saturation: Experimental and Empirical Contributions. Rock Mechanics and Rock Engineering. http://dx.doi.org/10.1007/s00603-018-1592-0
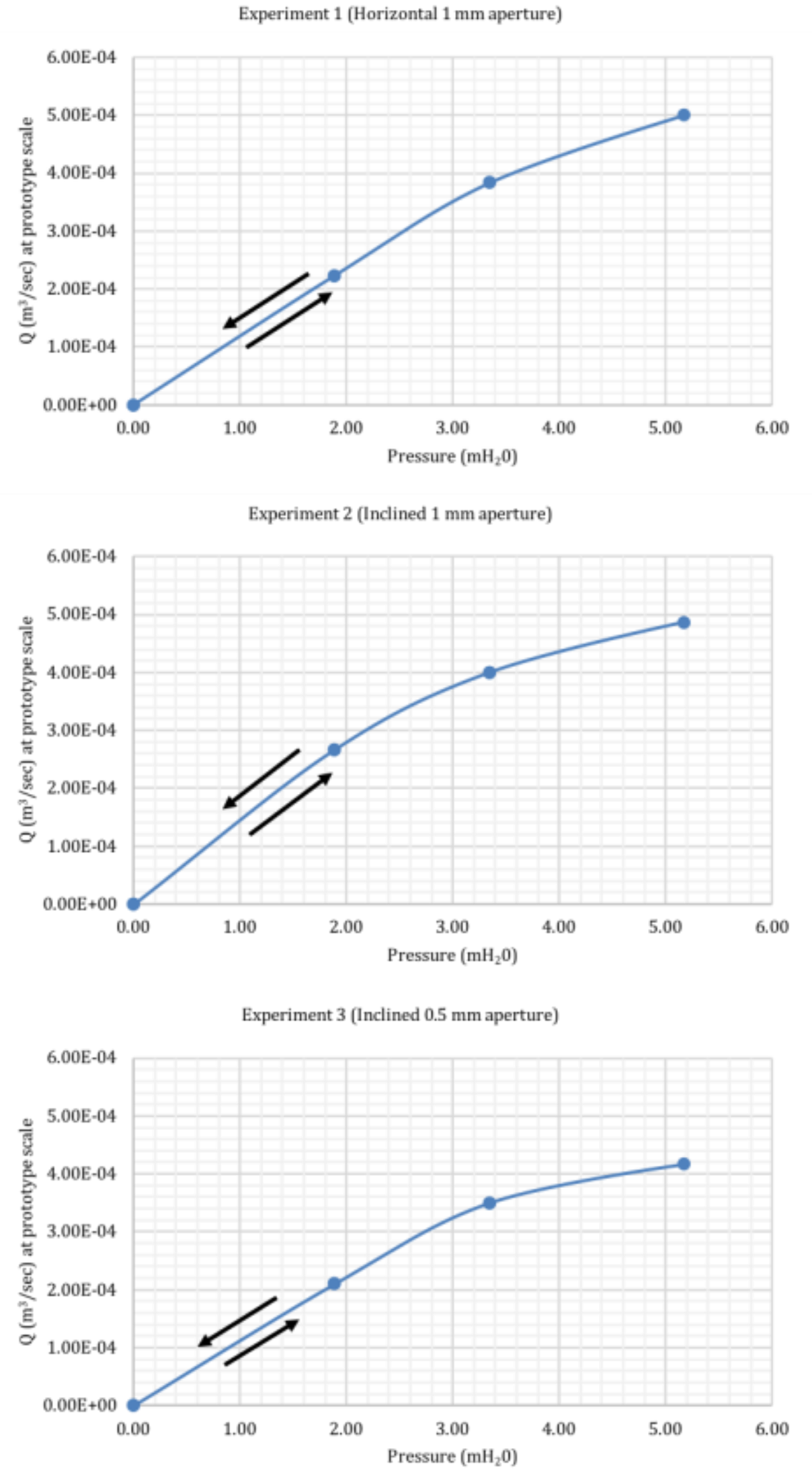

Fig. 9 Pressure versus flux $(P Q)$ diagrams per experiment 
The influence of the decrease in aperture is highlighted during Experiment $3(0.50 \mathrm{~mm}$ aperture), where all recorded fluxes are lower at the same hydraulic heads. The yield point at which linear behaviour ceases in Experiment 3 also occurs at the second hydraulic head. This can be explained by the effect that the decrease in aperture has on the hydraulic conductivity and resulting flux that can be accommodated through the fracture, which also acts to stabilises flow, and thus the onset of non-linear flow occurs gradually at increasing hydraulic heads.

Transmissivity was estimated using the Thiem equation, and the results presented in Table 3 . Values for the radius of influence cited in literature have been used in field studies where one could not directly observe the radius. However, due to the transparency of the acrylic sheets used in this study, the radius of influence is equivalent to the cross-sectional area of the saturated flow path within the fracture aperture (i.e. parallel to fracture), directly adjacent to the inlet pipe. All values used to calculate the transmissivities by Eq. 6 are prototype scale values.

Table 3 Calculated $T$ values, as well as $R e$ and $F_{o}$ numbers (at prototype scale) for the first pressure step in the experiments

\begin{tabular}{|l|l|l|l|l|}
\hline Model & $r_{o}(\mathrm{~mm})^{*}$ & $T\left(\mathrm{~m}^{2} \mathrm{~s}^{-1}\right)$ & $R e$ & $F_{o}$ \\
\hline Experiment 1 & $22(0.44 \mathrm{~m})$ & $3.85 \mathrm{E}-05$ & 698 & 1.86 \\
\hline Experiment 2 & $17(0.34 \mathrm{~m})$ & $3.19 \mathrm{E}-05$ & 881 & 1.18 \\
\hline Experiment 3 & $70(1.40 \mathrm{~m})$ & $4.97 \mathrm{E}-05$ & 169 & 0.50 \\
\hline${ }^{*}{ }^{r}=w$ &
\end{tabular}

\subsection{Reynold's Number $(R e)$ and Forchheimer Number $\left(F_{o}\right)$}

For fluid flow in fractures flow conditions are represented by the Reynold's Number $(R e)$ and Forcheimer Number $\left(F_{o}\right)$. Due to $R e$ not being uniquely defined over the radial flow area as the hydraulic gradient decreases away from the borehole wall along the fracture, following the approach used by both Iwai (1976) and Quinn et al. (2011), all $R e$ numbers are calculated for flow at the borehole wall where velocities are highest. The calculated $R e$ and $F_{o}$ the first pressure interval for each model is presented in Error! Reference source not found..

The volume of fluid flowing through the fracture renders the calculated Re high for both Experiment 1 and Experiment 2 (1 mm apertures). The $R e$ is however lower in the horizontal test (Experiment 1$)$ due to the lower flow rates, which is also likely a function of an increase in saturation around the borehole, which might act to 
stabilise flow due to the tendency to simpler single-phase flow conditions. The Re drops in Experiment $3(0.5$ $\mathrm{mm}$ aperture) due to the decrease in aperture, which results in a low hydraulic conductivity, resulting in a smaller flux through the fracture and a stabilisation of the flow path.

Considering previous results of laboratory experiments using single fractures (see for e.g. Konzuk and Kueper 2004; Nicholl et al. 1999; Zimmerman et al. 2004) who observed the onset of non-linear flow to occur between a $R e$ of between 1 and 5, the results presented here show that at the first pressure interval, flow has already entered the non-linear zone. The prevalence of this non-linear flow is in accordance with Widmann (1996), who states that flow is usually turbulent adjacent to a borehole during Lugeon tests due to the high flow velocities and associated pressure losses. Furthermore, the Forchheimer number $\left(F_{o}\right)$ at the lowest hydraulic head in each test is also far greater than published values, such as Zeng and Grigg (2006) who suggest a critical $F_{o}$ of 0.11 , and Macini et al. (2011) who suggest a critical $F_{o}$ of 0.40 . Based on the calculated $R e$ and $F_{o}$ number's, the deviation is attributed to inertial effects that contribute to increasing non-linearity, as the fluid bends at the entrance to the fracture from the inlet, which is a phenomenon observed by Iwai (1976) for radial flow from a borehole.

\subsection{Flow Mechanisms}

In the models tested, flow occurs as rivulets that constitute the minority of the fracture, and gradually increase in cross-sectional width upon at increasing hydraulic pressures. These preferential flow paths are highly anisotropic are characterised by instability, turbulence, non-uniformity, and irregularity. The flow paths in the inclined experiments are mostly characterised by a narrow width adjacent to the inlet (borehole), which widens further away to a maximum width, and then narrows again towards the fracture exit. Although lacking quantitative evidence, this could plausibly be the point identified by Widmann (1996), at which turbulent flow ceases and laminar flow establishes along the path. Notwithstanding, the widening outwards from the borehole to the position of the maximum width, is likely a function of the continuity principle, whereby a decrease in velocity results in an increase in saturation. The subsequent narrowing of the flow path width might thereafter be a function of the capillary barrier that is present at the short boundary of the fracture exit, which would result in a decrease in saturation and increase in velocity in order to breach the capillary barrier. 
The observation of this increase and subsequent narrowing of the flow path dimensions farther from the borehole, highlights the importance of the statement by Widmann (1996) who called for a better understanding of the change in flow path geometry. Importantly, this change in dimension away from the borehole is not a function of any geometrical fracture property, but rather a function of the phase conditions (i.e. two-phase flow due to unsaturated conditions) within the fracture itself. This is particularly critical considering the homogenous nature of the model fracture (i.e. smooth parallel plates).

The flow observations are a function of the prevalence of cohesion, which results in gravity-driven flow in the open non-horizontal (Experiment 2 and 3) fractures at the higher degrees of saturations when modelling the Lugeon test. The observation of wide rivulets for these inclined fractures (Experiment 2 and 3 ) are in accordance with $\mathrm{Su}$ et al. (1999) for rivulets supplied by high flow rates, as well as the flow regime boundary diagram presented by Ghezzehei (2004). The prevalence of these observed wide rivulets occur due to the higher contact angle (and therefore reduced wettability) of the acrylic sheets as the material is moderately hydrophobic.

Under increasing influxes conditions these flow paths become unstable and these wide rivulets exhibited a wavy surface. In order to identify the flow regime boundaries for these waves, the classification provided by Patnaik and Perez-Blanco (1996, as cited in Ghezzehei 2004) is utilised, where the $R e$ is multiplied by 4 to obtain the $R e_{s}$. The $R e_{s}$ value for all Experiment's is greater than 200, suggesting that the main cause of the perturbation is an inertial force, whereby for Experiment 3 the resulting waves are laminar $\left(200<R e_{s}<1000\right)$, and for Experiment 1 and Experiment 2 they are turbulent $\left(1000<R e_{s}<4000\right)$. The implication is that the observed waves roll over the substrate film at a much higher velocity than the substrate. The implication for this is that stable flow regimes (rivulets and film) do not apply in this range, but the flow is not yet fully turbulent (i.e. $R e_{s}$ is not greater than 4000).

The horizontal fracture (Experiment 1) mostly comprises fluid fingers which meander away from the inlet source (i.e. borehole). In contrast to the results presented by Jones et al. (2017a) the fracture does not fully saturate, because there is an insufficient volume of water provided from the inlet source to fully saturate the cross-sectional width of the fracture aperture (i.e. the cubic law flux), whilst the hydraulic head in this research is almost 2 orders of magnitude higher than the hydraulic heads recorded by Jones et al. (2017a). Unlike the experiments conducted 
by Jones et al. (2017a) who had a line source as their inlet, the inlet in these experiments is a much smaller point source, and is not be able to deliver the amount of fluid required to saturate the horizontal fracture.

\subsection{Prediction of Non-Linear Results}

In order to assess the non-linear results obtained in the experiments, the Forchheimer relationship as proposed by Schrauf and Evans (1986), in Eq. 4, was used to predict the flow rate of the models at the imposed hydraulic heads. This allowed for the measured experimental results to be compared against the predicted values (both at prototype scale). Considering that smooth parallel Plexiglas sheets are used in this study, a value of 12 for the coefficient $a_{D}$, and a friction factor $\left(f_{D}\right)$ of 0.064 is used (Chen et al. 2015b; Louis 1969; Schrauf and Evans 1986), resulting in the coefficient $b_{D}$ equalling 0.032 .

In order to calculate the Forchheimer relationship using Eq. 4, $w$ is assumed as the width of the flow path (crosssectional area of fracture at prototype scale) adjacent to the inlet pipe, rather than the full width of the fracture. However, the inherent problem with this approach is that the flow path width changes upon increasing the imposed hydraulic head. Nevertheless, due to the increase in width not being observed at the resolution of the experiments, a single representative width is used. The was deemed as appropriate due to the qualitative nature of the experimental data. The predicted flow $\left(\mathrm{m}^{3} / \mathrm{sec}\right)$ for the models at each tested hydraulic head $\left(\mathrm{mH}_{2} 0\right)$ is shown in Fig. 10. The Forchheimer equation is compared with respect to its ability to predict the observed $Q$ on the basis of the imposed hydraulic head $\left(\mathrm{mH}_{2} \mathrm{O}\right)$, with the results shown in Table 4.

Table 4 Comparison of predicted Forchheimer Equation with the measured data for each model (values are at prototype scale)

\begin{tabular}{|c|c|c|c|c|}
\hline Measured $d H(\mathrm{~m})$ & Measured $Q\left(\mathrm{~m}^{3} / \mathrm{sec}\right)$ & $\begin{array}{l}\text { Forchheimer } Q \\
\quad\left(\mathrm{~m}^{3} / \mathrm{sec}\right)\end{array}$ & $\begin{array}{l}w \text { at prototype scale } \\
(\mathrm{m})\end{array}$ & $\begin{array}{c}\text { Forchheimer } \% \\
\text { difference from } \\
\text { measured } d H\end{array}$ \\
\hline \multicolumn{5}{|c|}{ Horizontal $1 \mathrm{~mm}$} \\
\hline 1.9266 & $2.73 \mathrm{E}-04$ & $2.63 \mathrm{E}-04$ & \multirow{3}{*}{0.44} & $-3.7 \%$ \\
\hline 3.4112 & 3.83E-04 & $4.00 \mathrm{E}-04$ & & $+4.4 \%$ \\
\hline 5.2751 & $5.00 \mathrm{E}-04$ & $4.95 \mathrm{E}-04$ & & $-1.0 \%$ \\
\hline \multicolumn{5}{|c|}{ Inclined $1 \mathrm{~mm}$} \\
\hline 1.9266 & $2.67 \mathrm{E}-04$ & $2.68 \mathrm{E}-04$ & \multirow{3}{*}{0.34} & $+0.4 \%$ \\
\hline 3.4112 & $4.00 \mathrm{E}-04$ & $4.05 \mathrm{E}-04$ & & $+1.3 \%$ \\
\hline 5.2751 & 4.87E-04 & $4.93 \mathrm{E}-04$ & & $+1.2 \%$ \\
\hline \multicolumn{5}{|c|}{ Inclined $0.50 \mathrm{~mm}$} \\
\hline 1.9266 & $2.10 \mathrm{E}-04$ & $2.13 \mathrm{E}-04$ & \multirow{3}{*}{1.40} & $+1.4 \%$ \\
\hline 3.4112 & $3.50 \mathrm{E}-04$ & $3.34 \mathrm{E}-04$ & & $-4.8 \%$ \\
\hline 5.2751 & $4.17 \mathrm{E}-04$ & $4.36 \mathrm{E}-04$ & & $+4.6 \%$ \\
\hline
\end{tabular}


This is a postprint version of: Jones BR, Van Rooy JL, Dippenaar MA (2018) Lugeon Tests at Partial Saturation: Experimental and Empirical Contributions. Rock Mechanics and Rock Engineering. http://dx.doi.org/10.1007/s00603-018-1592-0

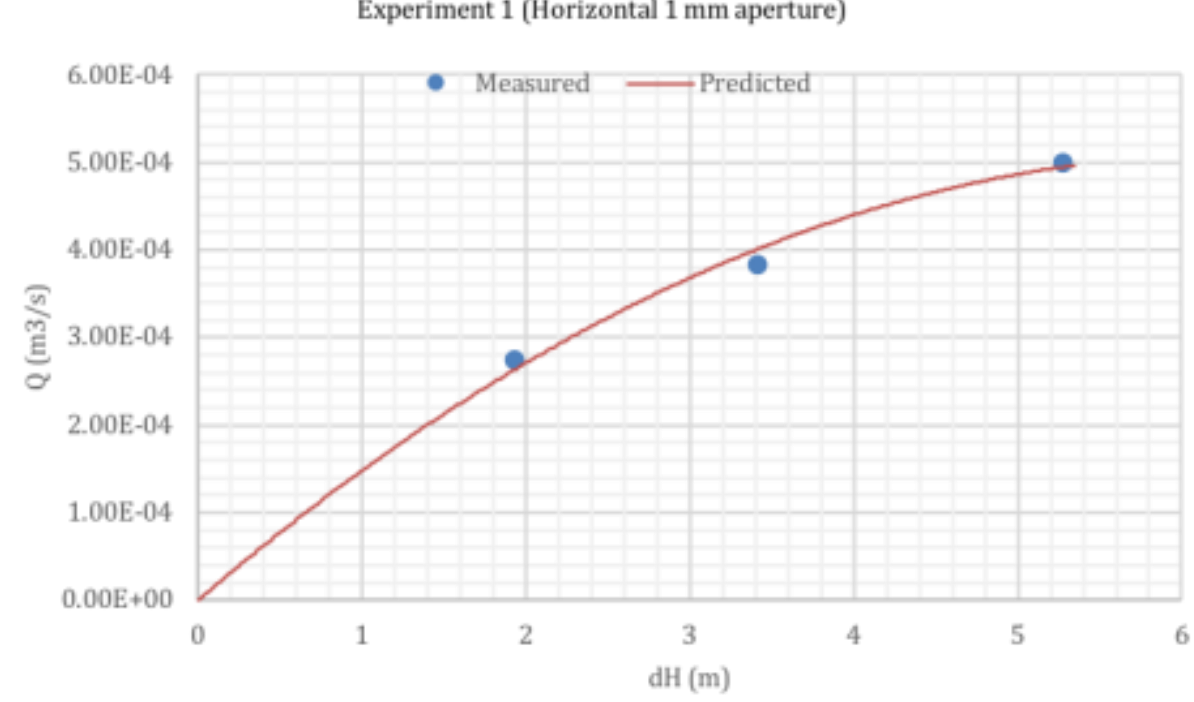

Experiment 2 (Inclined $1 \mathrm{~mm}$ aperture)

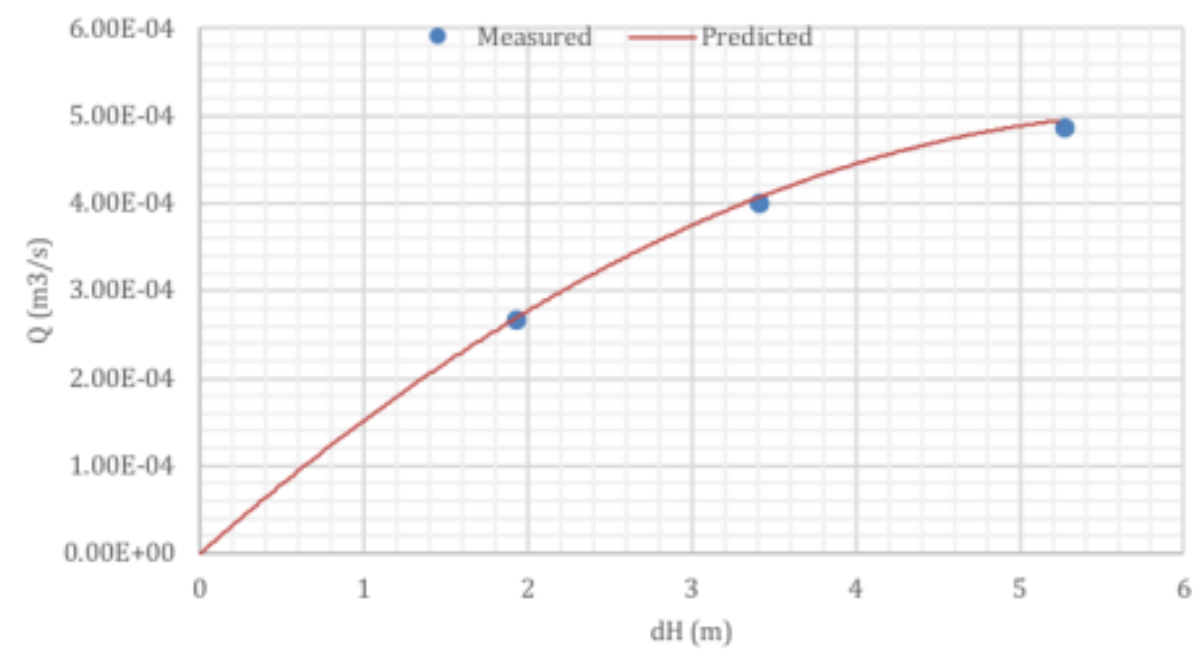

Experiment 3 (Inclined $0.5 \mathrm{~mm}$ aperture)

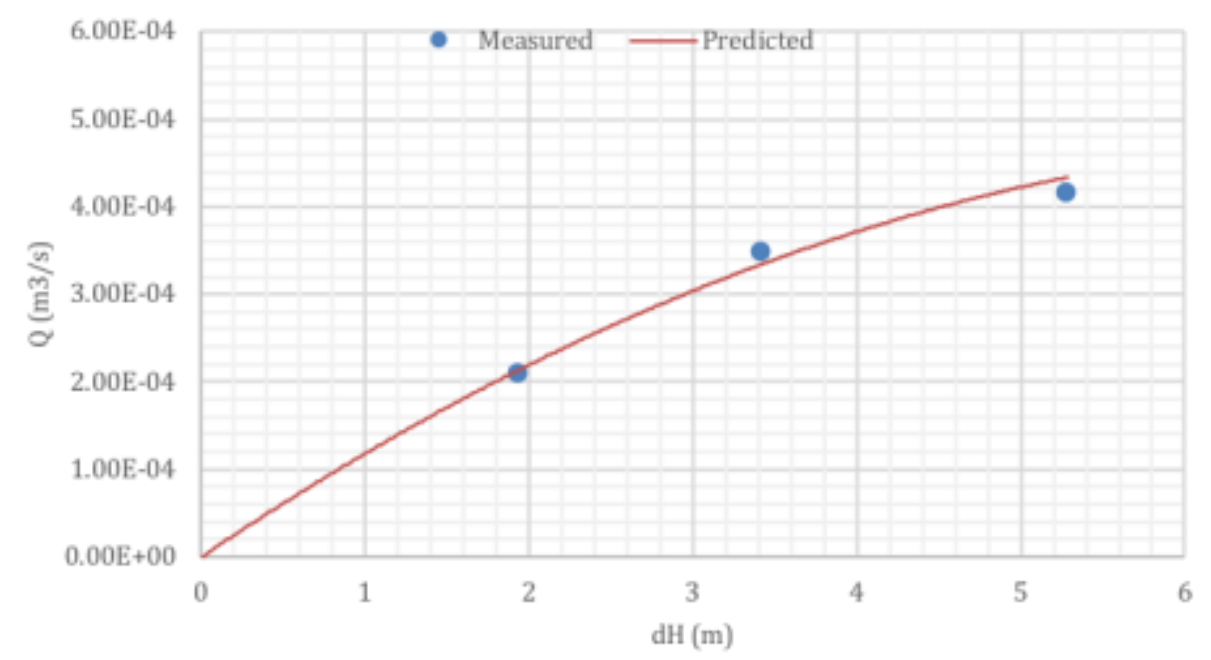

Fig. 10 Forchheimer prediction with measured values for each experiment 
For this comparison, the Forchheimer model predicted the $Q$ from the measured hydraulic pressure $(d H)$, and these results are compared to the measured $Q$. In general, the Forchheimer model performs well in predicting the measured $Q$ within the data collected for the experiments. The differences for all experiments show that the variance between the measured flow rate and the flow rate predicted by the Forchheimer model do not vary by more than $5 \%$ for any pressure interval in any of the centrifuge models tested. Experiment 2 (inclined $1 \mathrm{~mm}$ aperture) shows the best fit between the measured data from the centrifuge model and the flow rate predicted by the Forchheimer relationship.

By back-analysis, using the width of the flow path $(w)$ used in the Forchheimer relationship, and assuming a $R e$ of 5 (as cited in literature as being the critical value where linear flow cease), the $Q$ value at which flow deviates from linearity can be calculated. The calculated flow rates are summarised in Table 5 and shows that flow deviates from linearity at very small injections $(Q)$ for all centrifuge models tested.

Table 5 Measured flow rate (prototype scale) at which flow deviates from linearity assuming a $R e$ of 5 for all centrifuge models

\begin{tabular}{|l|l|l|l|}
\hline & Experiment 1 & Experiment 2 & Experiment 3 \\
\hline$Q\left(\mathrm{~m}^{3} / \mathrm{sec}\right)$ & $1.96 \times 10^{-6}$ & $1.51 \times 10^{-6}$ & $6.23 \times 10^{-6}$ \\
\hline
\end{tabular}

\section{CONCLUSION}

\subsection{Limitations and Lessons Learnt}

The research as discussed in this paper is limited to the smooth parallel acrylic fractures with open $(0.5 \mathrm{~mm}$ to 1 $\mathrm{mm}$ ), clean apertures, modelled at accelerated conditions in a geotechnical centrifuge. With this is mind, the hydraulic conductivity of fractures is dependent on the fracture aperture, roughness, infill, stress conditions and geometrical properties, and these properties will have needed to be represented accurately in subsequent studies. However, with little advancements with regards to the implications of partially saturated flow on permeability assessments, starting at fundamental concepts is essential. Notwithstanding, future experiments need to address the utilisation of better analogue rock material, as well as consideration of the fracture network (e.g. intersections of discrete fractures). Specifically, the materials used to address unsaturated flow in fractures will need to better mimic the surface characteristics (i.e. contact angle) such as promoting stable film flow on natural fracture surfaces. Furthermore, it was not possible to ensure that the potassium permanganate crystals did not influence 
the surface tension of the fluid used in the experiments; however, it is duly noted that the addition of the crystals could possibly influence the properties of the water.

Although this study aimed at quantifying the observed non-linear flow behaviour, it is duly noted that the calculation of the Forchheimer relationship is based on a fixed width at each interval. This is likely unrealistic, as in natural fractures where apertures are smaller, the cross-sectional area of saturation is likely to widen upon increasing hydraulic pressures. Therefore, using this approach will be difficult to adopt and estimate in practice. This possible widening in the cross-sectional area of saturation was difficult to quantify, as small increases in the width where not possible to observe as the scale was not at a resolution great enough to assess the increase in flow path width. Nevertheless, the Forchheimer relationship performs significantly well, but additional quantitative studies (both laboratory and field) are required to aid in developing better numerical models. At this stage, any further quantification of parameters using existing empirical approaches will obscure the findings, as most such approaches have very specific limitations, none of which this study aimed to duplicate.

\subsection{Main Findings and Way Forward}

An experimental study using geotechnical centrifuge modelling to investigate the flow behaviour during Lugeon tests through a smooth, clean, open fractures under conditions of variable saturation is undertaken. The major findings of the research presented in this paper is summarised as follows:

- Flow from the inlet source (representing a borehole) occurs as preferential paths of turbulent, nonuniform, irregular rivulets that occupy the minority of the fracture area. The observation of such anisotropy is critical considering the homogeneity (i.e. smooth, parallel, and open) of the model fractures.

- Flow rates are not proportional to the cube of the aperture in unsaturated fractures, and under these conditions, as gravitational forces increase, a linear flow relationship ceases and flow is instead characterised by a non-linear relationship.

- Assuming a critical Reynolds Number of 5, back-analysis indicates that flow deviates from non-linearity at small fluxes which is consistent with previously published literature. Furthermore, this deviation from linearity at small fluxes is likely as a result of inertial effects due to fluid bending at the inlet source into the fracture. 
- Deviation from linear flow occurs at higher hydraulic heads for flow in the inclined $0.50 \mathrm{~mm}$ aperture fracture (Experiment 3), as well as the horizontal fracture (Experiment 1). This can be attributed to the smaller aperture in Experiment 3, and the increased saturation in the fracture for Experiment 1, respectively. Conversely, deviation is observed at lower hydraulic heads in the inclined $1 \mathrm{~mm}$ aperture fracture (Experiment 2).

- Predicted results using the Forchheimer law compare well with the measured experimental results, when using the width of the flow path adjacent to the inlet source. The Forchheimer relationship has been used to describe non-linear flow in saturated fractures due to the effects of fracture geometry (e.g. roughness, aperture etc.) and it is shown here that it may also be useful to better quantify flow through discrete fractures in the fractured vadose zone.

Although the extrapolation of the results of this idealised model set-up to an in-situ rock mass is cautioned, the potential relevance of these fundamental findings to broader field applications cannot be ignored due to the repeated call for a systematic understanding of the preferential flow paths that govern rock mass permeability. In this regard, the observation of non-linear flow during Lugeon tests can result in a misinterpretation of the hydrological nature of the fractures within a rock mass. Non-linear (turbulent) flow behaviour during Lugeon tests is typically attributed to the presence of a rough fracture set (resulting in a pressure drop formed by eddies within the fracture). However, results presented here show that the observation of turbulent flow may instead be a function of the variably saturated conditions of the rock mass. Furthermore, Lugeon tests conducted in an initially unsaturated rock mass might misrepresent the hydrogeological regime, which would behave differently under saturated conditions. One can hypothetically exemplify this by considering Lugeon tests conducted within the intermediate vadose zone (unsaturated rock mass) during investigation of a dam site, and could lead to a mischaracterisation of the rock mass permeability. This misunderstanding would only become apparent once saturated phreatic conditions are achieved after reservoir impoundment.

Consider a discrete discontinuity, within a rock mass within the vadose zone, which intersects a Lugeon-test section being undertaken during the exploration phase of a reservoir site along the dam wall centreline footprint. Based on the experimental results presented, this fracture may result in the Lugeon-test pattern exhibiting a turbulent flow behaviour. In such an instance, the Lugeon-value is taken from the highest imposed hydraulic 
pressure. However, theoretically if the discontinuity is saturated, then flow should be laminar, and the Lugeonnumbers over all pressure stages are averaged to give the Lugeon-value. This will result in a lower Lugeon-value for the unsaturated discontinuity (during the exploration phase in the intermediate vadose zone) compared to the Lugeon-value of the saturated discontinuity (after reservoir impoundment and the subsequent formation of phreatic conditions), which will be higher.

The corresponding $P Q$ diagram for the unsaturated discontinuity is non-linear. Therefore, the flow recorded at the highest imposed hydraulic pressure (during the Lugeon-test would result in the incorrect estimation of the flux that is to occur through the fracture. During dam construction and subsequent reservoir impoundment, the rock mass becomes increasingly saturated (due to the formation of phreatic conditions). This saturation (single phase flow through a smooth parallel open fracture) theoretically should result in a linear flow relationship through this fracture. Therefore, under the imposed hydraulic head of the reservoir, the flux that occurs through the same discontinuity will be much higher than that estimated during the Lugeon-test during the exploration phase. Therefore, this leads to an underestimation of the hydraulic conductivity of the fracture, and shows how variably saturated fracture conditions can have different implications for a project over its life cycle (from investigation, to construction and monitoring). Notwithstanding, it is noted that this hypothetical example does not consider the complex effects of grouting operations. Although the findings are preliminary due to their fundamental concept, they have significant relevance in the investigation and design for dam sites, where rock mass permeability derived from Lugeon tests are overestimated. This lack of understanding fracture flow mechanisms in unsaturated conditions in the field, has recently been postulated by Jones et al. (2018) for a dam site.

The research has underlined primary issues with variably saturated flow through smooth, clean, open discontinuities. The relevance of how flow occurs through fractures at partial saturation in the rock engineering context is understated, especially given the quest to achieve better quantification of permeability calculations from Lugeon tests. The results prove that using broad empirical correlations to define hydraulic conductivities of Lugeon test intervals from $\mathrm{Lu}$-values should be cautioned. Classical volume-effective approaches do not contribute to fundamental research questions, and require a deeper understanding of the small-scale processes in the porous fractured systems that characterize the intermediate fractured vadose zone. Ultimately, finding a suitable representation of an analogous fractured rock mass is difficult, and at process scale's the best one can do 
is to isolate individual processes. Although fundamental studies are gradually improving our understanding, many more studies are required to obtain a unified view of unsaturated (preferential) flow through fractures. More importantly, additional studies will allow to link observed processes in between scales. Ultimately, continued research into each isolated process, will formulate a clear understanding of how flow occurs through discrete unsaturated fractures, before the necessary and more precise quantification of how-much flow occurs through these fractures.

\section{REFERENCES}

Aydin A (2001) Fracture void structure: implications for flow, transport and deformation Environmental Geology

: International Journal of Geosciences 40:672-677

Barry D, Lisle I, Li L, Prommer H, Parlange JY, Sander GC, Griffioen J (2001) Similitude applied to centrifugal scaling of unsaturated flow Water Resources Research 37:2471-2479

Bear J (1972) Dynamics of fluids in porous media American Elsevier, New York

Berkowitz B (2002) Characterizing flow and transport in fractured geological media: A review Advances in Water Resources 25:861-884 http://dx.doi.org/10.1016/S0309-1708(02)00042-8

Brouwers LB, Dippenaar MA (2018) Partially saturated flow from sand into a discrete smooth open vertical fracture at the soil-rock interface: experimental studies Bulletin of Engineering Geology and the Environment https://www.doi.org/10.1007/s10064-018-1258-X

Brush DJ, Thomson NR (2003) Fluid flow in synthetic rough- walled fractures: Navier- Stokes, Stokes, and local cubic law simulations Water Resources Research 39

Chen Y-F, Liu M-M, Hu S-H, Zhou C-B (2015a) Non-Darcy's law-based analytical models for data interpretation of high-pressure packer tests in fractured rocks Engineering Geology 199:91-106 doi:http://dx.doi.org/10.1016/j.enggeo.2015.10.011

Chen Y-F, Zhou J-Q, Hu S-H, Hu R, Zhou C-B (2015b) Evaluation of Forchheimer equation coefficients for nonDarcy flow in deformable rough-walled fractures Journal of Hydrology 529, Part 3:993-1006 doi:http://dx.doi.org/10.1016/j.jhydrol.2015.09.021

Cherubini C, Giasi CI, Pastore N (2012) Bench scale laboratory tests to analyze non-linear flow in fractured media Hydrol Earth Syst Sci 16:2511-2522 doi:10.5194/hess-16-2511-2012 
This is a postprint version of: Jones BR, Van Rooy JL, Dippenaar MA (2018) Lugeon Tests at Partial Saturation: Experimental and Empirical Contributions. Rock Mechanics and Rock Engineering. http://dx.doi.org/10.1007/s00603-018-1592-0

Cook N (1992) Natural joints in rock: Mechanical, hydraulic and seismic behaviour and properties under normal stress International Journal of Rock Mechanics and Mining Sciences \& Geomechanics Abstracts 29:198223

Croisé J, Schlickenrieder L, Marschall P, Boisson J, Vogel P, Yamamoto S (2004) Hydrogeological investigations in a low permeability claystone formation: the Mont Terri Rock Laboratory Physics and Chemistry of the Earth, Parts A/B/C 29:3-15

Culligan P, Barry D (1998) Similitude requirements for modelling NAPL movement with a geotechnical centrifuge Proc Instn Civ Engrs Geotech Engng:180-186

Culligan-Hensley PJ, Savvidou C (1995) Environmental geomechanics and transport processes In: Taylor R (ed) Geotechnical centrifuge technology. CRC Press, pp 201-271

Della Volpe C, Maniglio D, Morra M, Siboni S (2002) The determination of a 'stable-equilibrium'contact angle on heterogeneous and rough surfaces Colloids and Surfaces A: Physicochemical and Engineering Aspects 206:47-67

Dippenaar MA, van Rooy JL (2016) On the cubic law and variably saturated flow through discrete open roughwalled discontinuities International Journal of Rock Mechanics and Mining Sciences 89:200-211 doi:http://dx.doi.org/10.1016/j.ijrmms.2016.09.011

Dippenaar MA, van Rooy JL (2019) Vadose Zone Characterisation for Hydrogeological and Geotechnical Applications. In: Shakoor A., Cato K. (eds) IAEG/AEG Annual Meeting Proceedings, San Francisco, California, 2018 - Volume 2. Springer, Cham. https://doi.org/10.1007/978-3-319-93127-2_10

Doe TW (2001) What do drops do? Surface wetting and network geometry effects on vadose-zone fracture flow Conceptual models of flow and transport in the fractured vadose zone:243-270

Dragila MI, Weisbrod N (2003) Parameters affecting maximum fluid transport in large aperture fractures Advances in Water Resources 26:1219-1228

Ewert F Discussion of Rock Type Related Criteria for Curtain Grouting. In: Proceedings of the Third International Conference on Grouting and Ground Improvement, ASCE Special Publication, 2003. vol 120.

Ewert F-K (1985) Rock grouting with emphasis on dam sites. Springer-Verlag, Berlin ;

Ewert F-K Evaluation and interpretation of water pressure tests. In: Bell AL (ed) Grouting in the ground. , 1992.

Thomas Telford, London, pp 141-162 
This is a postprint version of: Jones BR, Van Rooy JL, Dippenaar MA (2018) Lugeon Tests at Partial Saturation: Experimental and Empirical Contributions. Rock Mechanics and Rock Engineering. http://dx.doi.org/10.1007/s00603-018-1592-0

Ewert F-K (1997a) Permeability, groutability and grouting of rocks related to dam sites. Part 1: Grouting examples and ground water flow in rock Dam Engineering 8:31-76

Ewert F-K (1997b) Permeability, groutability and grouting of rocks related to dam sites. Part 2: Permeability testing by means of water pressure tests Dam Engineering 8:123-176

Forchheimer P (1901) Wasserbewegung durch boden Zeitz Ver Duetch Ing 45:1782-1788

Garnier J et al. (2007) Catalogue of scaling laws and similitude questions in geotechnical centrifuge modelling International Journal of Physical Modelling in Geotechnics 7:1

Ghezzehei TA (2004) Constraints for flow regimes on smooth fracture surfaces Water Resources Research 40:n/an/a doi:10.1029/2004WR003164

Gustafson G, Fransson $\AA$ (2006) The use of the Pareto distribution for fracture transmissivity assessment Hydrogeology Journal 14:15-20

Haimson BC, Doe TW (1983) State of stress, permeability, and fractures in the Precambrian granite of northern Illinois Journal of Geophysical Research: Solid Earth 88:7355-7371

Hamm S-Y, Kim M, Cheong J-Y, Kim J-Y, Son M, Kim T-W (2007) Relationship between hydraulic conductivity and fracture properties estimated from packer tests and borehole data in a fractured granite Engineering Geology 92:73-87 doi:http://dx.doi.org/10.1016/j.enggeo.2007.03.010

Heitfeld KH, Krapp L (1981) The problem of water permeability in dam geology Bulletin of the International Association of Engineering Geology - Bulletin de l'Association Internationale de Géologie de l'Ingénieur 23:79-83 doi:10.1007/bf02594730

Houlsby A (1976) Routine interpretation of the Lugeon water-test Quarterly Journal of Engineering Geology and Hydrogeology 9:303-313

Iwai K (1976) Fundamental studies of fluid flow through a single fracture. Ph. D. Thesis, Univ., California, Barkeley

Jacobsz S, Kearsley E, Kock J The geotechnical centrifuge facility at the University of Pretoria. In: ICPMG2014Physical Modelling in Geotechnics: Proceedings of the 8th International Conference on Physical Modelling in Geotechnics 2014 (ICPMG2014), Perth, Australia, 14-17 January 2014, 2014. CRC Press, p 169

Javadi M, Sharifzadeh M, Shahriar K, Mitani Y (2014) Critical Reynolds number for nonlinear flow through rough- walled fractures: The role of shear processes Water Resources Research 50:1789-1804 
Jones BR, Brouwers LB, Dippenaar MA (2017a) Partially to fully saturated flow through smooth, clean, open fractures: qualitative experimental studies Hydrogeology Journal doi:http://dx.doi.org/10.1007/s10040017-1680-3

Jones BR, Brouwers LB, Van Tonder WD, Dippenaar MA (2017b) Assessing geotechnical centrifuge modelling in addressing variably saturated flow in soil and fractured rock Environmental Science and Pollution Research 24:13203-13223 doi:https://doi.org/10.1007/s11356-016-8333-2

Jones BR, Van Rooy JL, Mouton DJ (2018) Verifying the Ground Treatment as Proposed by the Secondary Permeability Index during Dam Foundation Grouting Bulletin of Engineering Geology and the Environment doi:https://doi.org/10.1007/s10064-017-1219-9

Jones BR, Van Rooy JL, Dippenaar MA (2019) On the Differing Role of Contact Obstacles on Variably Saturated Flow in Vertical and Horizontal Fractures. In: Shakoor A., Cato K. (eds) IAEG/AEG Annual Meeting Proceedings, San Francisco, California, 2018 - Volume 4. Springer, Cham. https://doi.org/10.1007/9783-319-93133-3_11

Kayabasi A, Yesiloglu-Gultekin N, Gokceoglu C (2015) Use of non-linear prediction tools to assess rock mass permeability using various discontinuity parameters Engineering Geology 185:1-9 http://dx.doi.org/10.1016/j.enggeo.2014.12.007

Konzuk JS, Kueper BH (2004) Evaluation of cubic law based models describing single-phase flow through a rough-walled fracture Water Resources Research 40: http://dx.doi.org/10.1029/2003WR002356

Ku C-Y, Hsu S-M, Chiou L-B, Lin G-F (2009) An empirical model for estimating hydraulic conductivity of highly disturbed clastic sedimentary rocks in Taiwan Engineering Geology 109:213-223

Kurikami H, Takeuchi R, Yabuuchi S (2008) Scale effect and heterogeneity of hydraulic conductivity of sedimentary rocks at Horonobe URL site Physics and Chemistry of the Earth, Parts A/B/C 33:S37-S44

Lancaster-Jones P (1975) The interpretation of the Lugeon water-test Quarterly Journal of Engineering Geology and Hydrogeology 8:151-154

Le Borgne T, Bour O, Riley M, Gouze P, Pezard P, Belghoul A, Lods G, Le Provost R, Greswell RB, Ellis PA (2007) Comparison of alternative methodologies for identifying and characterizing preferential flow paths in heterogeneous aquifers Journal of Hydrology 345:134-148

Lee C-H, Farmer IW (1993) Fluid flow in discontinuous rocks. 1st ed. edn. Chapman \& Hall, London ; 
Louis C (1969) Étude des écolements d'éau dans les roches fissurées et de leur influence sur la stabilité des massifs rocheurs BRGM Bulletin de la Direction des Études et Récherches Serie A(3):5-132

Macini P, Mesini E, Viola R (2011) Laboratory measurements of non-Darcy flow coefficients in natural and artificial unconsolidated porous media Journal of Petroleum Science and Engineering 77:365-374

Maini YN (1972) In situ hydraulic parameters in jointed rock: their measurement and interpretation. University of London

Mejías M, Renard P, Glenz D (2009) Hydraulic testing of low-permeability formations: A case study in the granite of Cadalso de los Vidrios, Spain Engineering Geology 107:88-97

Mollah MA, Sayed SA (1995) Assessment of in situ permeability with emphasis on packer testing in Kuwait Engineering geology 39:217-231

Nappi M, Esposito L, Piscopo V, Rega G (2005) Hydraulic characterisation of some arenaceous rocks of Molise (Southern Italy) through outcropping measurements and Lugeon tests Engineering Geology 81:54-64 doi:http://dx.doi.org/10.1016/j.enggeo.2005.07.007

Neuman SP (2005) Trends, prospects and challenges in quantifying flow and transport through fractured rocks Hydrogeology Journal 13:124-147

Nicholl M, Glass R, Wheatcraft S (1994) Gravity- driven infiltration instability in initially dry nonhorizontal fractures Water Resources Research 30:2533-2546

Nicholl M, Rajaram H, Glass R, Detwiler R (1999) Saturated flow in a single fracture: Evaluation of the Reynolds equation in measured aperture fields Water Resources Research 35:3361-3373

Nonveiller E (2013) Grouting theory and practice vol 57. Elsevier

Öge İF, Çırak M (2017) Relating rock mass properties with Lugeon value using multiple regression and nonlinear tools in an underground mine site Bulletin of Engineering Geology and the Environment doi:10.1007/s10064-017-1179-0

Or D, Ghezzehei TA (2007) Traveling liquid bridges in unsaturated fractured porous media Transport in Porous Media 68:129-151

Or D, Tuller M (2000) Flow in unsaturated fractured porous media: Hydraulic conductivity of rough surfaces Water Resources Research 36:1165-1177

Palmstrom A, Stille H (2010) Rock engineering. Thomas Telford, London, United Kingdom 
This is a postprint version of: Jones BR, Van Rooy JL, Dippenaar MA (2018) Lugeon Tests at Partial Saturation: Experimental and Empirical Contributions. Rock Mechanics and Rock Engineering. http://dx.doi.org/10.1007/s00603-018-1592-0

Patnaik V, Perez-Blanco H (1996) Roll waves in falling films: an approximate treatment of the velocity field International journal of heat and fluid flow 17:63-70

Pearson R, Money MS (1977) Improvements in the Lugeon or packer permeability test Quarterly Journal of Engineering Geology and Hydrogeology 10:221-239 doi:10.1144/gsl.qjeg.1977.010.03.05

Phillips R (1995) Centrifuge modelling: practical considerations Geotechnical centrifuge technology:34-60

Pyrak LR, Myer LR, Cook NGW (1985) Determination of fracture void geometry and contact area at different effective stress. Eos Trans AGU 66

Quinn PM (2009) High Resolution Packer Testing in Fractured Sedimentary Rock. University of Waterloo

Quinn PM, Cherry JA, Parker BL (2011) Quantification of non- Darcian flow observed during packer testing in fractured sedimentary rock Water Resources Research 47

Quiñones-Rozo C Lugeon test interpretation, revisited. In: Collaborative Management of Integrated Watersheds, 30rd Annual USSD (United States Society on Dams) Conference. US Society on Dams, Denver, 2010. pp 405-414

Ranjith P, Darlington W (2007) Nonlinear single- phase flow in real rock joints Water Resources Research 43

Raven KG, Gale JE (1985) Water flow in a natural rock fracture as a function of stress and sample size International Journal of Rock Mechanics and Mining Sciences 22:251-261

Royle MR (2002) Standard operating procedures for borehole packer testing, p 22.

Ruth D, Ma H (1992) On the derivation of the Forchheimer equation by means of the averaging theorem Transport in Porous Media 7:255-264

Schrauf T, Evans D (1986) Laboratory studies of gas flow through a single natural fracture Water Resources Research 22:1038-1050

Silberhorn-Hemminger A, Süß M, Helmig R (2005) Natural fractured porous systems. In: Dietrich P, Helmig, R., Sauter, M., Hötzl, H., Köngeter, J., and Teutsch, G. (ed) Flow and transport in fractured porous media. . Springer, Berlin, pp 16-24

Singhal BBS, Gupta RP (2010) Applied hydrogeology of fractured rocks. 2nd ed. edn. Springer, Dordrecht ;

Sisavath S, Al-Yaaruby A, Pain CC, Zimmerman RW (2003) A Simple Model for Deviations from the Cubic Law for a Fracture Undergoing Dilation or Closure Pure and Applied Geophysics 160:1009-1022

Su GW, Geller JT, Pruess K, Wen F (1999) Experimental studies of water seepage and intermittent flow in unsaturated, rough-walled fractures Water Resources Research 35:1019-1037 
Taylor R (1995) Centrifuges in modelling: Principles and scale effects. In: Taylor R (ed) Geotechnical centrifuge technology. CRC Press, pp 20-34

Tokunaga TK, Wan J (1997) Water film flow along fracture surfaces of porous rock Water Resources Research $33: 1287-1295$

Tokunaga TK, Wan J (2001) Approximate boundaries between different flow regimes in fractured rocks Water Resources Research 37:2103-2111

Van Tonder WD, Jacobsz SW (2017) Seepage column hydraulic conductivity tests in the geotechnical centrifuge Journal of the South African Institution of Civil Engineering 59:16-24

Weaver KD, Bruce DA (2007) Dam Foundation Grouting. ASCE Press,

Wenzel LK (1936) The Thiem method for determining permeability of water-bearing materials and its application to the determination of specific yield; results of investigations in the Platte River valley, Nebraska. US Department of the Interior, Geological Survey,

Widmann R International society for rock mechanics commission on rock grouting. In: International Journal of Rock Mechanics and Mining Sciences \& Geomechanics Abstracts, 1996. vol 8. Elsevier, pp 803-847

Witherspoon PA (1986) Flow of groundwater in fractured rocks Bulletin of the International Association of Engineering Geology 34:103-115

Yihdego Y (2017) Hydraulic In situ Testing for Mining and Engineering Design: Packer Test Procedure, Preparation, Analysis and Interpretation Geotechnical and Geological Engineering 35:29-44 doi:10.1007/s10706-016-0112-9

Zeigler TW (1976) Determination of Rock Mass Permeability. Army Engineer Waterways Experiment Station, Vicksburg

Zeng Z, Grigg R (2006) A criterion for non-Darcy flow in porous media Transport in porous media 63:57-69

Zhou J-Q, Hu S-H, Fang S, Chen Y-F, Zhou C-B (2015) Nonlinear flow behavior at low Reynolds numbers through rough-walled fractures subjected to normal compressive loading International Journal of Rock Mechanics and Mining Sciences 80:202-218 doi:http://dx.doi.org/10.1016/j.ijrmms.2015.09.027

Zimmerman RW, Al-Yaarubi A, Pain CC, Grattoni CA (2004) Non-linear regimes of fluid flow in rock fractures International Journal of Rock Mechanics and Mining Sciences 41, Supplement 1:163-169 doi:http://dx.doi.org/10.1016/j.ijrmms.2004.03.036 
This is a postprint version of: Jones BR, Van Rooy JL, Dippenaar MA (2018) Lugeon Tests at Partial Saturation: Experimental and Empirical Contributions. Rock Mechanics and Rock Engineering. http://dx.doi.org/10.1007/s00603-018-1592-0

Zimmerman RW, Yeo IW (2000) Fluid Flow in Rock Fractures: From the Navier-Stokes Equations to the Cubic Law Dynamics of fluids in fractured rock:213-224 